REPORT

on

\title{
ANALYSIS OF CERAMIC MATERIALS FOR IMPACT MEMBERS IN ISOTOPIC HEAT SOURCES
}

to

NUCLEAR RESEARCH AND APPLICATIONS DIVISION

ENERGY RESEARCH AND DEVELOPMENT ADMINISTRATION

May 14, 1976

by

F. A. Simonen and W. H. Duckworth

Contract W-7405-eng-92, Task 67

BATTELLE

Columbus Laboratories

505 King Avenue

Columbus, Ohio 43201 


\section{DISCLAIMER}

This report was prepared as an account of work sponsored by an agency of the United States Government. Neither the United States Government nor any agency Thereof, nor any of their employees, makes any warranty, express or implied, or assumes any legal liability or responsibility for the accuracy, completeness, or usefulness of any information, apparatus, product, or process disclosed, or represents that its use would not infringe privately owned rights. Reference herein to any specific commercial product, process, or service by trade name, trademark, manufacturer, or otherwise does not necessarily constitute or imply its endorsement, recommendation, or favoring by the United States Government or any agency thereof. The views and opinions of authors expressed herein do not necessarily state or reflect those of the United States Government or any agency thereof. 


\section{DISCLAIMER}

Portions of this document may be illegible in electronic image products. Images are produced from the best available original document. 


\section{REPORT}

on

ANALYSIS OF CERAMIC MATERIALS FOR IMPACT MEMBERS

IN ISOTOPIC HEAT SOURCES

to

NUCLEAR RESEARCH AND APPLICATIONS DIVISION

ENERGY RESEARCH AND DEVELOPMENT ADMINISTRATION

May 14,1976

by

F. A. Simonen and W. H. Duckworth

Contract W-7405-eng-92, Task 67

BATTELLE

Columbus Laboratories

505 King Avenue

Columbus, Ohio 43201

This report was prepared as an account of work

sponsored by the United States Government Nesther

the United States nor the United States Energy

ther employes, nor any of therr, nortract or

subcontractors, or their employees makes any

warranty, express or impled, or assumes any legal

Labulty or responsibility for the accuracy, completeness

or usefulness of any information, apparatus, product or

process disclosed, or represents that its use would not

infringe pnvately owned rights 


\section{FOREWORD}

This report is submitted by Battelle's Columbus Laboratories to summarize research conducted under ERDA Contract W-7405-eng-92, Task 67. A. P. Litman represented ERDA/SNS* as Program Manager and F. L. Bagby served as the Battelle-Columbus Program Manager. Major contributions to the report were provided by the following Battelle staff members:

W. H. Duckworth, Task Leader, and Ceramic Materials Technology

F. A. Simonen, Impact Member Stress Analysis .

The research described in this report was part of a larger technology program concerned with impact member and heat shield materials for heat sources used in space power generation. The results of this study have broad application in evaluating structural ceramics where they are applied under conditions of high stress loadings.

* Subsequent to the preparation of this report and prior to its issue, Space Nuclear Systems (SNS) Division of ERDA became part of a new Division, Nuclear Research and Applications (NRA). 
$\underline{\text { Page }}$

INTRODUCTION. . . . . . . . . . . . . . . . . . . 1

SUMMARY . . . . . . . . . . . . . . . . . . . . . 3

BACKGROUND ON IMPACT MEMBER PROBLEM . . . . . . . . . . . . . 4

DEFINITION OF RANKING PARAMETERS. . . . . . . . . . . . . 6

Contact Stress Parameter $-\mathrm{R}_{1}$. . . . . . . . . . . . . 8

Geometry Effect Parameter - $\mathrm{R}_{2}$. . . . . . . . . . . 10

Stress Wave Parameter $-\mathrm{R}_{3}$. . . . . . . . . . . . . 13

RANKING OF HIGH STRENGTH CERAMICS . . . . . . . . . . . . . . 15

DETAILED ANALYSIS OF SILICON NITRIDE IMPACT MEMBER. . . . . . . . . 17

Effect of Shell Thickness. . . . . . . . . . . . . . 18

Dynamic Versus Quasi-Static Analysis . . . . . . . . . . 18

Effect of Target Deformation . . . . . . . . . . . 20

Effect of Fuel . . . . . . . . . . . . . . . . . 26

FABRICATION CONSIDERATIONS FOR CERAMIC IMPACT MEMBER. . . . . . . . 33

STRUCTURAL DESIGNING WITH CERAMIC MATERIALS . • • • • • • • • • • . 35

CONCLUSIONS AND RECOMMENDATIONS . . . . . . . . . . . . . . 39

REFERENCES. . . . . . . . . . . . . . . . . . . . 4 40

\section{LIST OF TABLES}

Table 1. Summary of Ranking Parameters Used in Screening of High Strength Ceramics in Impact Response . . . . . . . . 7

Table 2. Ranking of Materials for Impact Performance on the Basis of Elastic Response . . . . . . . . . . . . 16

\section{LIST OF FIGURES}

Figure 1. Fuel Sphere for MHW Heat Source. . . . . . . . . . 2

Figure 2. Analytical Mode1 for Ranking Parameter $R_{1}$ for Hertzian Contact Stresses. . . . . . . . . . . . 9

Figure 3. Finite-Element Analysis of Elastic Impact Stresses in Spherical Shell for Ranking Parameter $R_{2}$. . . . . . . 11

Figure 4. Analytical Model for Ranking Parameter $R_{3}$ for Stress Wave Propagation Conditions . . . . . . . . . 14 
TABLE OF CONTENTS

(continued)

$\underline{\text { Page }}$

LIST OF FIGURES

Figure 5. Stress in Silicon Nitride Spheres When Impacted

Against Rigid Target. . . . . . . . . . . . . .

Figure 6. Stresses in Hollow Silicon Nitride Sphere as

Calculated by Computer Code HONDO for Impact

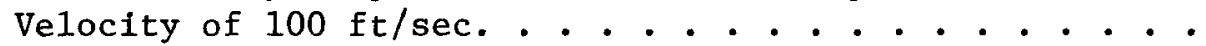

Figure 7. Stresses in Solid Silicon Nitride Sphere as

Calculated by Computer Code HONDO for Impact

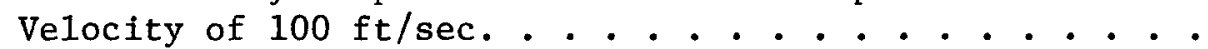

Figure 8. Response of Trailing Surface of Impacting Silicon

Nitride Sphere as Calculated by Computer Code

HONDO for Impact Velocity of $100 \mathrm{ft} / \mathrm{sec}$. . . . . . . 23

Figure 9. Effect of Target Deformation on Impact Response

of a Solid Silicon Nitride Sphere as Calculated

by Computer Code HONDO for Impact Velocity of

$100 \mathrm{ft} / \mathrm{sec}$. . . . . . . . . . . . . . . . 24

Figure 10. Stresses in Solid Silicon Nitride Sphere as

Calculated by Computer Code HONDO for Impact

Velocity of $100 \mathrm{ft} / \mathrm{sec}$, Showing Effect of

Target Deformation. . .............. 25

Figure 11. Stresses in Hollow Silicon Nitride Sphere as

Calculated by Computer Code HONDO for Impact

Velocity of $100 \mathrm{ft} / \mathrm{sec}$ Onto Rigid Target,

Showing Effect of Fuel Within Sphere. . . . . . . . . 28

Figure 12. Finite-Element Model of Hollow Silicon Nitride

Sphere With Fuel for Analysis of Impact With

Granite Target. . . . . . . . . . . . . . . . .

Figure 13. Calculated Stresses From HONDO for $100 \mathrm{ft} / \mathrm{sec}$

Impact of Hollow Silicon Nitride Sphere With

Granite Target; Fue1 Assumed to be Strong

(Unyielding) and Bonded to Silicon Nitride. . . . . . 30

Figure 14. Calculated Stresses From HONDO for $100 \mathrm{ft} / \mathrm{sec}$

Impact of Hollow Silicon Nitride Sphere With

Granite Target; Fuel Assumed to be Weak (Yielding)

and Bonded to Silicon Nitride. . . . . . . . . . . .

Figure 15. Calculated Hoop Stresses in Silicon Nitride Sphere at $64 \times 10^{-6} \mathrm{sec}$ for $100 \mathrm{ft} / \mathrm{sec}$ Impact With Granite Target; Fuel Assumed to be Weak (yielding) and Not Bonded to Silicon Nitride . . . . . . . . . . . 32

Figure 16. Failure Probability Curves for an $\mathrm{Al}_{2} \mathrm{O}_{3}$ Ceramic . . . . 37 


\section{ANALYSIS OF CERAMIC MATERIALS FOR IMPACT MEMBERS \\ IN ISOTOPIC HEAT SOURCES}

by

F. A. Simonen and W. H. Duckworth

\section{INTRODUCTION}

Since January, 1975, Battelle's Columbus Laboratories has been evaluating and testing advanced bulk and composite ceramic materials that might serve as improved impact and heat shield members for isotopic heat sources. A major goal in this research is the development and demonstration of a bifunctional material that would serve as a combined impact member and heat shield. This report presents the results of the analytical study of the impact response of high strength refractory ceramics. Other efforts in the research program on impact member materials have been directed primarily toward experimental and analytical studies of carbon-carbon composites.

The studies attempt to develop insight relating to advanced materials concepts. For reference, Figure 1 shows the current1y used spherical heat source from the Multi-Hundred Watt (MHW) Radioisotope Thermoelectric Generator (RTG) being developed by General Electric's Space Division. This concept was originally motivated by the desire to obtain an all-ceramic heat source. As indicated in Figure 1 , the only metallic portion is a $0.020-i n$-thick iridium clad which separates the ${ }^{238} \mathrm{PuO}_{2}$ fuel from the carbon impact shell. This iridium post-impact containment shell (PICS) is to provide positive fuel containment in the event of impact with loss of carbon shell continuity in "cushioning" the fuel.

In the analytical study of ceramics, elastic response models were utilized which assumed that the stress-strain behavior of the ceramic materials was linear elastic up to the point of fracture. Once the tensile strength of the brittle ceramic material was exceeded at any location within the member, catastrophic fracture was assumed to occur. If fracture did not occur, it was assumed that elastic rebound from an unyielding target resulted. 


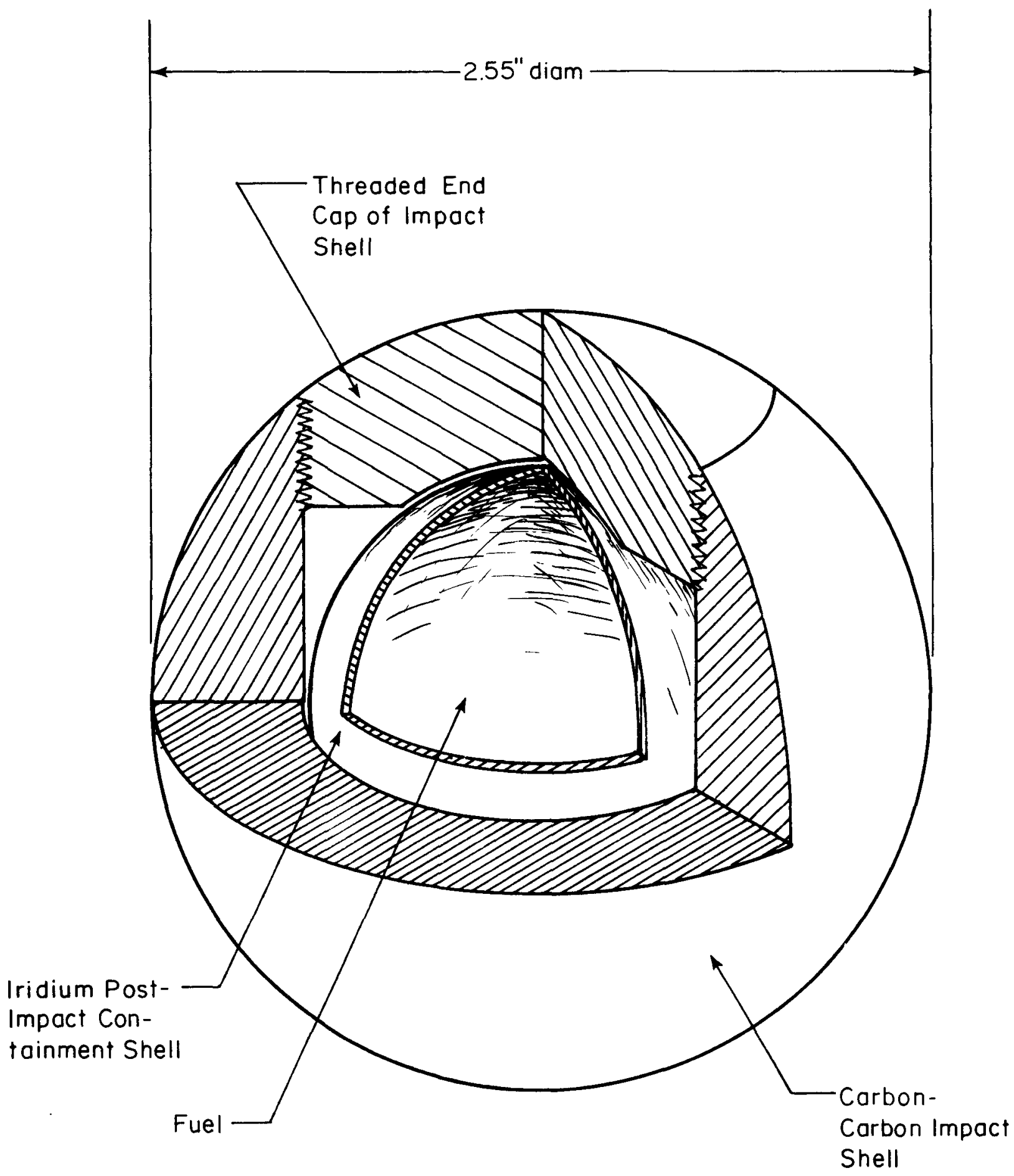

FIGURE 1. FUEL SPHERE FOR MHW HEAT SOURCE 
The comparison and evaluation of high strength ceramics was made on the basis of performance in a representative model of a spherical heat source. This heat source included a spherical ceramic outer shell to provide impact protection and containment of the enclosed fuel. A set of ranking parameters was developed and applied to show relative impact velocity capabilities of the candidate materials. These parameters accounted for the sensitivity of shell fracture to material properties (strength, modulus, and density) as well as target properties. Out of the ranking process, several preferred ceramic materials were identified as having the best impact performance among the candidates. Of these preferred materials, silicon nitride $\left(\mathrm{Si}_{3} \mathrm{~N}_{4}\right)$ was selected for further study, and a detailed study of the dynamic response of a silicon nitride impact member was conducted using the finiteelement computer program HONDO.

This report describes the analyses and conclusions relative to the use of high strength ceramic materials in heat source impact applications. Limitations in impact performance are identified and discussed, and anticipated problems in the fabrication and design of heat sources using structural ceramic materials are identified and discussed. The results will apply to cylinders, parallelepipeds, etc., as well as spherical shapes.

\section{SUMMARY}

A procedure for comparing the relative impact performance of ceramic materials was developed on the basis of a set of three ranking parameters which were first defined. The basis and significance of these parameters are presented and discussed in detail. The parameters are then applied to compare the performance of a list of candidate high strength ceramic materials. Silicon nitride is identified as offering the most promise, followed by aluminum oxide and silicon carbide.

Extensive stress analyses of a heat source with a silicon nitride impact member were performed using a finite-element computer code for structural dynamics analyses. Factors such as target compliance, fuel strength, and fuel-to-ceramic bond strength were studied in order to define the impact velocity limitations of a ceramic impact member. 
It was determined that allowable impact velocities for a heat source with a ceramic impact member of less than $100 \mathrm{ft} / \mathrm{sec}$ could be expected, with the impact performance being limited in part by present-day ${ }^{238} \mathrm{PuO}_{2}$ ceramic fuels which have relatively low strengths. The stress analyses show that the presence of a strong and unyielding fuel would reduce stresses in a ceramic impact member. If, in the future, stronger fuels can be developed, one could expect allowable impact velocities of $200 \mathrm{ft} / \mathrm{sec}$ or greater. Techniques to bond the fuel to a ceramic shell would also be required. Even to achieve impact velocities in the 100 to $200 \mathrm{ft} / \mathrm{sec}$ range, some form of additional limited impact protection would be required to distribute or "cushion" the high contact stress acting on the ceramic shell at the point of impact. Consideration of the fabrication and design problems associated with a ceramic impact member indicates that an extensive development effort would be required for their resolution.

It is concluded that ceramic materials have limited potential for present-generation heat source impact member applications. Recommendations for future research by NRA in this area do not appear justified. However, the procedure described in this report for ranking ceramic materials will prove useful in screening all ceramic materials including bulk and composite graphites. The latter group of materials are, and will continue to be, extensively used in heat sources and in isotopic power systems.

\section{BACKGROUND ON IMPACT MEMBER PROBLEM}

The use of a radioisotope heat source in space presents a potential hazard in that under special circumstances an aborted mission or orbital decay might result in the release of radioactive ${ }^{238} \mathrm{PuO}_{2}$. The present approach $(1)^{*}$ to avoiding this possibility is that of packaging the fuel within multiple layers of materials so that its containment is assured after atmospheric reentry and earth impact. This report focuses on the possibility of structura1

* References are listed on page 40. 
failure due to impact on unyielding granite (idealized design condition). The optimum heat source under these conditions is one that provides assured fuel containment in the event of earth impact with minimum overall system weight.

Impact velocities of present interest range from 100 to $500 \mathrm{ft} / \mathrm{sec}$, with one contemporary system being in the range of $300 \mathrm{ft} / \mathrm{sec}$. In normal heat source operation, the ${ }^{238} \mathrm{PuO}_{2}$ fuel is at temperatures ranging upward to $1400 \mathrm{C}$, and accordingly the impact member must be made from a material that is both heat resistant and heat conductive. The requirement for heat resistance is imposed by the need to prevent 1ong-term degradation of properties, while conductivity is required to allow the proper thermal flux to reach the thermal-electric converters on the exterior of the heat source. Ideally, this conductivity would be decreased during reentry so that the materials will serve as an insulator and protect the isotope fuel from excessive temperatures from exterior reentry heating that might lead to melting, increased helium release, or interaction potential. (Most of the required thermal reentry protection is provided by the heat shield.)

In al1 recent designs of RTG's, the radioisotope heat source has been contained within a graphite shell for protection against reentry heating. Upon impact, the remaining thickness of graphite ( $250 \%$ ) fractures in a brittle manner and is not expected to ease the impact of the heat source. In the present systems, primary containment of the fuel is provided by a metallic shell. This will probably be a requirement of future systems also, due to handling, assembly, and radioactive characteristics. In the type of heat source such as used in the SNAP-19 Pioneer and Viking RTG ${ }^{(2)}$, the metal shell serves as a structural containment and impact member which helps to prevent lateral expansion of the fuel and consequently fuel capsule deformation and rupture upon impact. In the more recent MHW design ${ }^{(3)}$, the metallic shell serves only a containment function, with energy absorption and strength being provided by a carbon-carbon composite outer impact shell around the individual modules.

Certain advantages of using ceramics in place of metals have long been recognized. The requirement that heat sources operate at elevated temperatures for extended time periods limits the designer in the selection 
of metals to refractory and noble metals and their alloys which are expensive. Metallurgical stability is required at service temperature to maintain strength and ductility of the metals. A severe limitation of the refractory metals is their tendency to interact to varying degrees with ${ }^{238}{ }^{\mathrm{PuO}_{2}}$ fuel and to oxidize at elevated temperatures when exposed to ambient earth environments for extended time periods. The latter condition is present after earth impact, and prevention of eventual exposure of fuel to the environment cannot be assured. In contrast, refractory ceramics offer stability and can be oxidation-free when exposed for long periods of time at elevated temperatures. Thus, if a ceramic containment shell could withstand the stresses imposed from earth impact, the ceramic could provide fuel containment for indefinite time periods. There are also obvious disadvantages of ceramics, chief among those are their characteristic brittle fracture mode and their associated low impact resistance and sensitivity to stress concentrations. Also, fabrication difficulties must be overcome in order to assemble a ceramic shell over a contained fuel and to incorporate a vent into the assembly to permit the release of helium gas generated from radioactive decay of the fuel.

The study described below is strictly analytical in nature. The purpose was to determine if a ceramic impact shell could realistically be expected to withstand stresses imposed during reasonable impact. The effort involved a systematic review of present-day, high strength and high melting point ceramics in the context of heat source applications. The results of this feasibility study form a basis for decisions on possible future developmental and test programs and demonstrate the utility of interdisciplinary analytical studies in evaluating speculative thoughts on materials selection.

\section{DEFINITION OF RANKING PARAMETERS}

In order to compare the relative performance of materials on the basis of property data, a set of three material ranking parameters was developed. The parameters were applied to estimate the velocity at which impact members of high strength ceramic materials could strike an unyielding target without fracturing. Reported mechanical properties of the candidate ceramic materials were used for this study. 
A ranking parameter, as conceived in this study, serves to relate the performance of a material (impact-velocity capability) to relevant material properties (strength, elastic modulus, and density). Such parameters were derived on the basis of simplified stress analyses of representative impact conditions. Thus, the calculated values of ranking parameters for different materials are intended to show the relative impact-velocity capability of one material compared to another. The results are intended to be indicative of performance rather than precise evaluations.

A total of three ranking parameters were defined, and these are listed in Table 1. Each parameter considered a different mode of deformation and associated stress state which can govern the brittle fracture of a ceramic material under impact conditions. Each of these parameters is described and evaluated below.

TABLE 1. SUMMARY OF RANKING PARAMETERS USED IN SCREENING OF HIGH STRENGTH CERAMICS IN IMPACT RESPONSE

Ranking Parameter

$R_{1}$ - Contact Stress Parameter

$\mathrm{R}_{2}$ - Geometry Effect Parameter

$R_{3}$ - Stress Wave Parameter

\section{Factors Considered}

Local Hertzian contact stresses and the way fracture due to these stresses is governed by the strength of the impact member and the elastic moduli of both impact member and target.

Stresses due to bending in a shell, and how fracture due to these stresses is governed by the strength, elastic modulus, and mass density of the impact member material.

Stresses due to stress wave propagation, and how fracture due to these stresses is governed by the strength of the impact member and the moduli and mass density of both impact member and target. 
Contact Stress Parameter $-\mathrm{R}_{1}$

When a ceramic spherical shape contacts a hard, unyielding surface, as in impact, high local stresses result in the very small region where the surface of the sphere is actually in contact with the impacted target, as shown in Figure 2. The analysis of such stresses is described in the references on the subject of the mathematical theory of elasticity under the title of Hertzian contact stresses (e.g., Reference 4). Fracture of brittle ceramic materials is governed by the maximum tensile stress in the contact region. Through manipulation of contact stress equations, the following ranking parameter for impact-velocity capabilities can be derived:

$$
R_{1}=16.59 \frac{\sigma_{t}^{5 / 2}}{\rho^{1 / 2}}\left(\frac{1}{E}+\frac{1}{E_{t}}\right)^{2}, \mathrm{ft} / \mathrm{sec},
$$

where

$$
\begin{aligned}
\rho & =\text { density of fuel, } 1 \mathrm{~b} / \mathrm{in} .^{3} \\
\sigma_{t} & =\text { tensile strength of ceramic outer shell, psi } \\
E & =\text { modulus of ceramic outer shell, psi } \\
E_{t} & =\text { modulus of target, psi. }
\end{aligned}
$$

This equation indicates the importance of a high tensile strength $\left(\sigma_{t}^{5 / 2}\right)$, while density $\left(\rho^{1 / 2}\right)$ is a much less critical factor in determining allowable impact velocity. The contact stress analysis shows the stress to be a function of the overall mass of the sphere and it was assumed that the fuel density, rather than impact shell density, is the primary contributor to the overall mass of the sphere. The above equation also shows that a low value of elastic modulus tends to enhance impact performance.

The analysis for the parameter $R_{1}$ applies to the impact of two hard, unyielding materials without the presence of a cushioning medium between the materials. Fractures are found to occur in the manner suggested by the analysis when, for example, glass is subjected to impact and a characteristic conical fracture surface initiates at the impact point. The analysis applies 


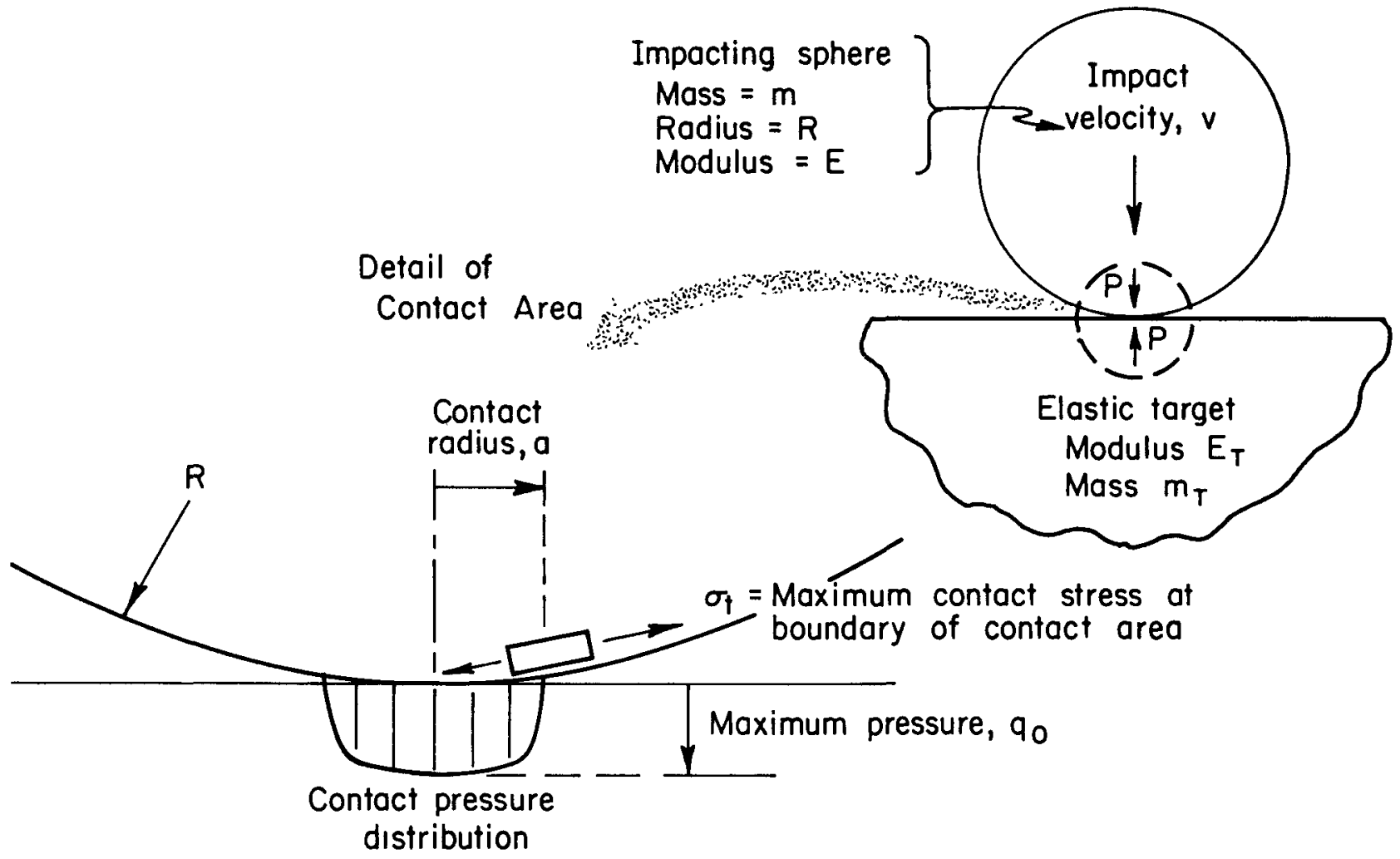

FIGURE 2. ANALYTICAL MODEL FOR RANKING PARAMETER $R_{1}$ FOR HERTZIAN CONTACT STRESSES 
in particular only to initiation of fractures at the contact point and does not imply that sufficient energy is available to produce total fracture of the impacting ceramic. Experimentally such fractures appear as arrested cracks originating from the point of contact. The value of tensile strength used to predict fracture initiation due to local contact stresses was treated as a deterministic property of the material. This is an oversimplification of the actual situation. Fracture of a brittle ceramic is initiated at defects in the material. Since contact stresses are only very local in nature, the probability of a large defect in the region of high stress would be less than in a mechanical test where more of the bulk of the material is subjected to high stresses. Accordingly, the appropriate strength of the material for use in the above equation could be greater than that indicated by standard tensile and bend tests on the material. A detailed discussion of the factors that affect the strength of ceramic materials is given in a separate section below.

Some uncertainty exists as to the ability of the above equation to predict absolute values of impact velocities to induce contact stress fractures in ceramic materials. This is mainly due to uncertainties in defining fracture stress. Nevertheless, we believe the equation provides a reliable guide to comparing the performance under high contact stress of different ceramic materials.

Geometry Effect Parameter - $\mathrm{R}_{2}$

In defining this ranking parameter, $R_{2}$, the impact of a hollow ceramic sphere was considered. The dynamic stresses were estimated on the basis of the finite element, stress analysis model of a hollow sphere as shown in Figure 3.

If the local Hertzian contact stresses do not result in catastrophic fracture, failure will occur at a location remote from the contact point as the impact shell responds dynamically to the impact loadings. Impact-point fracture can be prevented if the contact stresses are distributed by a layer of deformable material (e.g., metallic outer shell) or crushable material 


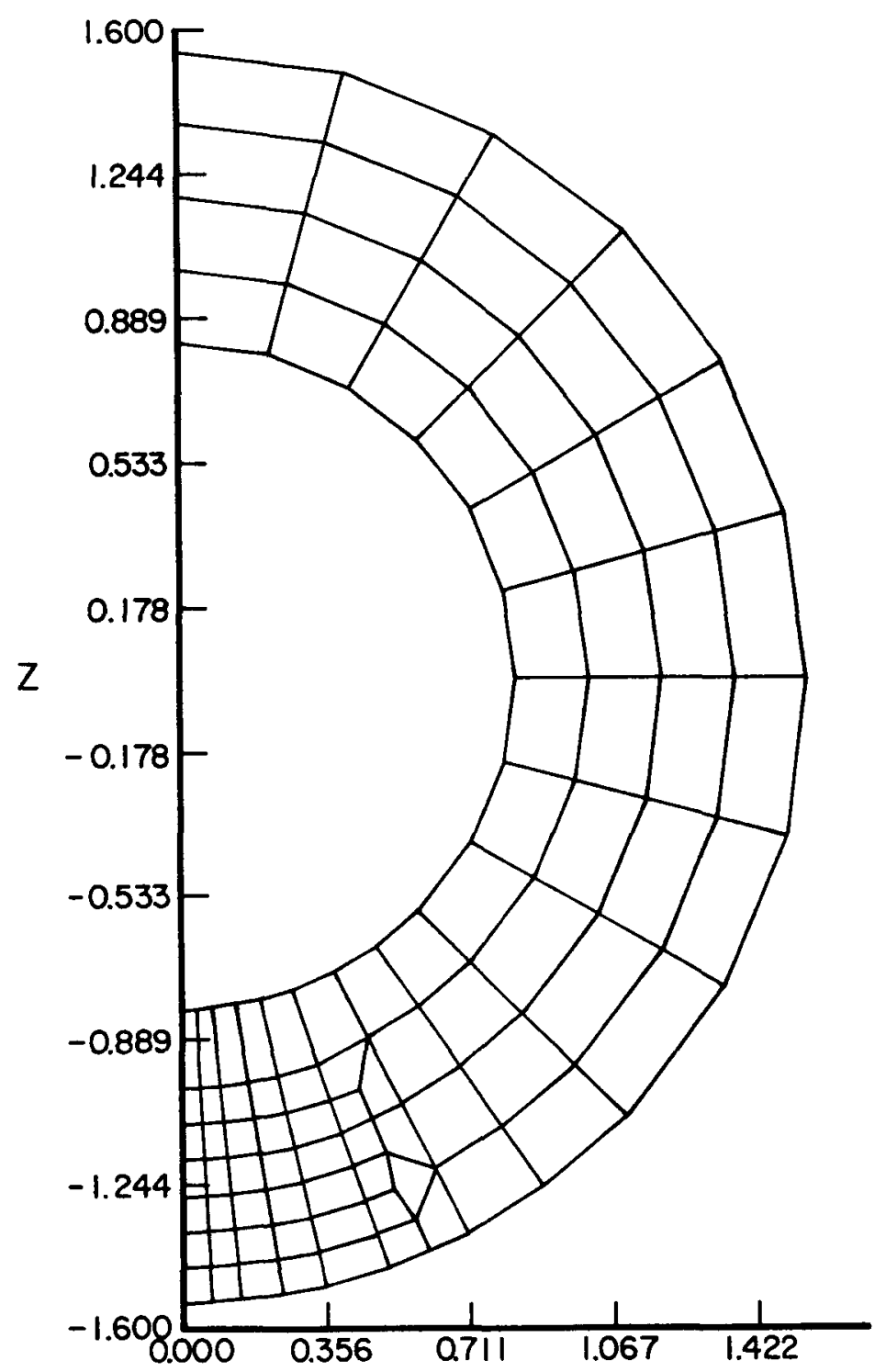

a. Finite-Element Model

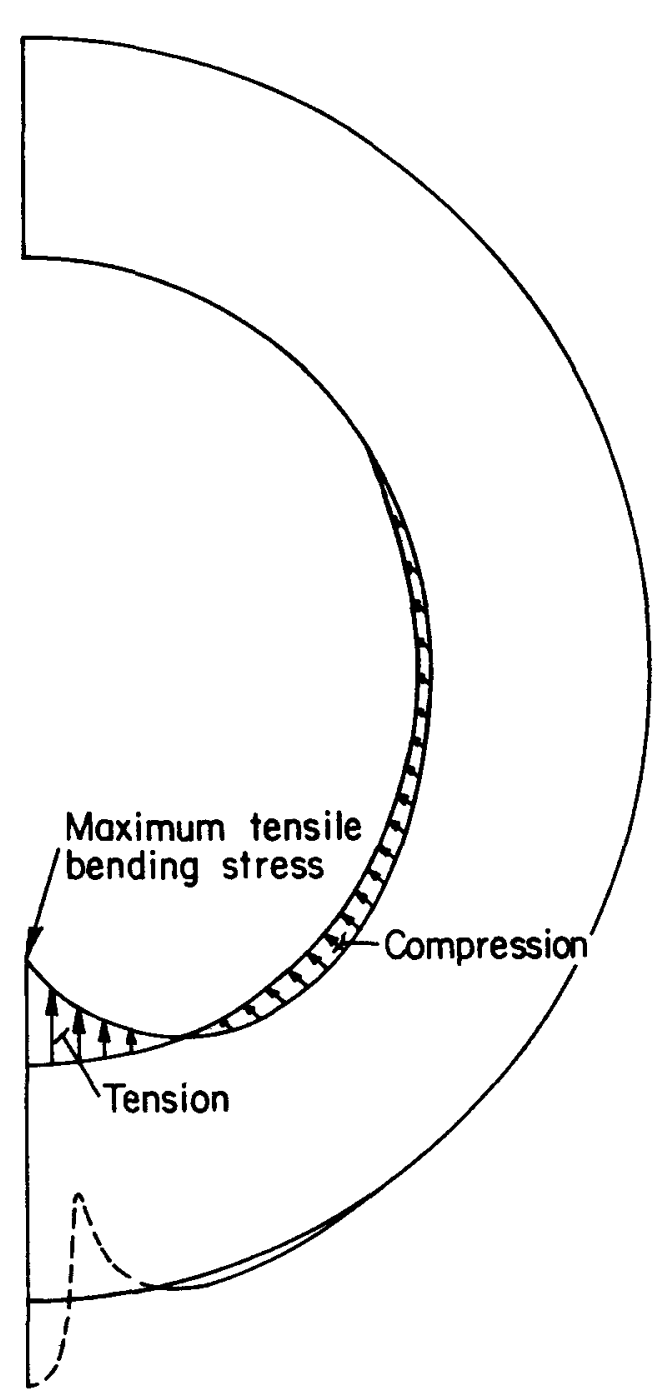

F

FIGURE 3. FINITE-ELEMENT ANALYSIS OF ELASTIC IMPACT STRESSES IN SPHERICAL SHELL FOR RANKING PARAMETER $\mathrm{R}_{2}$ 
(e.g., outer layer of carbon-carbon composite). A rigid target was assumed, and the effect of fuel within the she11 was not considered. It was reasonable for ranking purposes to first require that a ceramic impact shell be capable of withstanding impact without the added presence of loads imposed by the fuel on the ceramic she11. Consideration of mechanical fuel interactions was not within the scope of the initial material ranking effort. Subsequent analyses as reported below show that the $R_{2}$ type of stress is insensitive to the presence of the fuel for the case of a weak and yielding fuel. However, for a strong fuel which is bonded to the ceramic she1l, the stress in the ceramic shell is substantially less than that for the corresponding hollow sphere.

A finite-element stress analysis indicated that the critical tensile stress was of a bending nature, and occurred at the inside surface of the sphere directly opposite the impact point. It was found that the allowable impact velocity, defined as the ranking parameter $R_{2}$, could be expressed in the form

$$
R_{2}=K(\lambda) \sigma_{t} / \sqrt{E_{\rho}},
$$

where

$$
\begin{aligned}
\lambda & =\text { measure of contact area } \\
\mathrm{K}(\lambda) & =\text { function defined by finite-element analysis } \\
\sigma_{t} & =\text { tensile strength of ceramic } \\
E & =\text { elastic modulus of ceramic } \\
\rho & =\text { density of ceramic. }
\end{aligned}
$$

This equation shows the impact performance to be directly proportional to the tensile strength of the ceramic. Performance is also enhanced by low values of modulus and density.

The function, $K(\lambda)$, and the contact area parameter, $\lambda$, were determined from a series of finite-element stress analyses for a hollow ceramic sphere using the model of Figure 3. These analyses were performed on the basis of static considerations, with the dynamic inertial loading applied 
as a distributed body-force loading to the hollow elastic sphere. An energy method was used to relate stored elastic strain energy to kinetic energy of the impacting sphere. In this way stresses in the ceramic sphere were related to elastic modulus, density, and impact velocity.

Stress Wave Parameter $-\mathrm{R}_{3}$

The ranking parameter $R_{3}$ was defined in order to consider an upper limit on impact velocity, and also to include the effect of the relative moduli and densities of the assumed granite target and impacting ceramic.

The analytical model, as shown in Figure 4, was one of a short rod of the ceramic material striking a long rod of the target material (e.g., granite). Such a condition might be approached if a solid ceramic sphere were to impact under conditions where the contact stresses were very wel1 distributed by cushioning material. In an impact of the assumed type, a compressive stress wave is generated at the impact point and propagates into the impacting material at sonic velocity. The level of compressive stress can be calculated from the equations governing wave propagation in elastic materials as given in Reference 4.

The ranking parameter $R_{3}$ is a measure of the impact velocity required to induce a compressive stress equal to the compressive strength of the material. This parameter is defined as

$$
R_{3}=\frac{\sigma_{c}}{\sqrt{E \rho}}\left[1+\sqrt{\frac{E \rho}{E_{t} \rho_{t}}}\right] \text {, }
$$

where

$$
\begin{aligned}
\sigma_{c} & =\text { compressive strength of ceramic } \\
E & =\text { elastic modulus of ceramic } \\
\rho & =\text { density of ceramic } \\
E_{t} & =\text { modulus of target } \\
\rho_{t} & =\text { density of target. }
\end{aligned}
$$




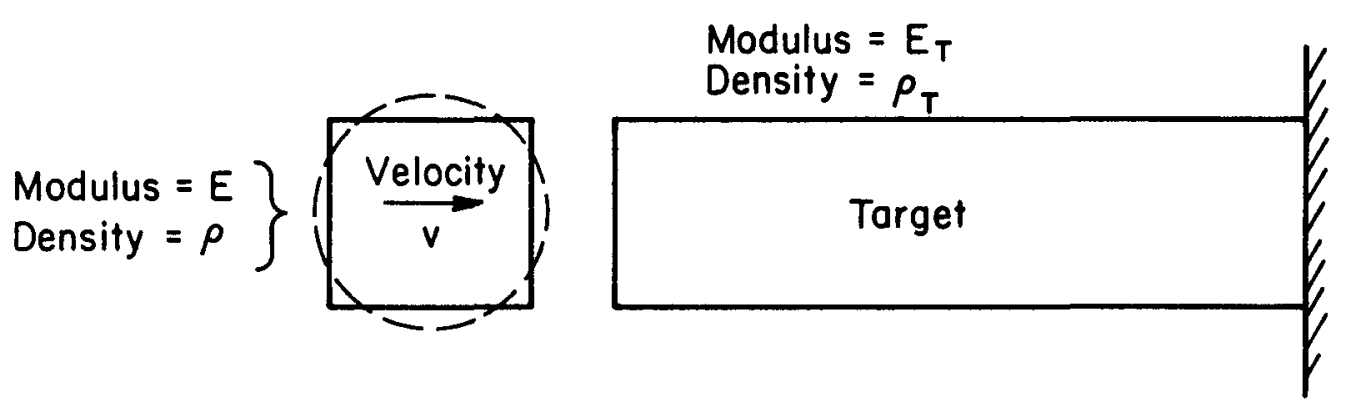

FIGURE 4. ANALYTICAL MODEL FOR RANKING PARAMETER $R_{3}$ FOR STRESS WAVE PROPAGATION CONDITIONS 
It is of interest that the strength, modulus, and density of the ceramic enter the analysis in exactly the same manner as for the case of the analysis for the parameter $R_{2}$.

\section{RANKING OF HIGH STRENGTH CERAMICS}

Numerous ceramic materials with high strengths and high melting points have been studied for various purposes, and were evaluated in this study. Table 2 lists a selected grouping of ceramics which could be of interest for heat source applications. Also listed for purposes of comparison is a high strength commercial bulk graphite (Poco).

Table 2 gives the results obtained in applying the parameters $R_{1}$, $R_{2}$, and $R_{3}$ to the listed materials. Also given are the values of material properties used in the ranking procedure. Density and modulus values for all materials are all based on well-established data. However, judgement at times was used in selecting strength values. Considerable variation in strengths can occur for a given ceramic material depending on processing details. Most of the high strength ceramics exhibit tensile strengths as normally measured in the range of 50,000 to 100,000 psi. Strengths in the upper level of this range can generally be achieved in a given ceramic if extensive development efforts are applied to the material. However, as discussed earlier, the achievable level can differ from the usable level in a structural application. For ranking purposes, room-temperature strength levels were used. Most ceramics will retain strength up to temperatures of $1000 \mathrm{C}$ or higher, above which rapid softening occurs with increasing temperature. At these higher temperatures viscous behavior and reduced strengths are observed. Compressive strengths of ceramics are difficult to measure, since under compressive loading fracture usually results from secondary tensile stresses that develop in the specimen. For purposes of calculating the ranking parameter $R_{3}$, it was assumed that the compressive strengths of the materials were twice the tensile strength. Such an assumption is conservative. Carbon composites are not included in this table, but will be treated in a subsequent report on this task since the ranking parameters are applicable only to isotropic elastic materials. 
TABLE 2. RANKING OF MATERIALS FOR IMPACT PERFORMANCE ON THE BASIS OF ELASTIC RESPONSE

\begin{tabular}{|c|c|c|c|c|c|c|}
\hline \multirow[b]{2}{*}{ Materia1 } & \multirow[b]{2}{*}{$\begin{array}{c}\text { Density, } \\
\text { g/cc }\end{array}$} & \multirow[b]{2}{*}{$\begin{array}{c}\text { Modulus, } \\
\text { psi }\end{array}$} & \multirow[b]{2}{*}{$\begin{array}{c}\text { Tensile } \\
\text { Strength, } \\
\text { psi }\end{array}$} & \multicolumn{3}{|c|}{ Ranking Parameters } \\
\hline & & & & $\begin{array}{c}R_{1}, \\
\mathrm{ft} / \mathrm{sec}\end{array}$ & $\begin{array}{c}R_{2}, \\
\mathrm{ft} / \mathrm{sec}\end{array}$ & $\begin{array}{c}R_{3}, \\
\mathrm{ft} / \mathrm{sec} \\
\end{array}$ \\
\hline $\mathrm{MoSi}_{2}$ & 6.2 & $63 \times 10^{6}$ & 50,000 & 6.2 & 10.0 & 228 \\
\hline $\mathrm{wSi}_{2}$ & 9.3 & $50 \times 10^{6}$ & 50,000 & 6.5 & 8.9 & 225 \\
\hline $\mathrm{TaSi}_{2}$ & 9.1 & $50 \times 10^{6}$ & 50,000 & 6.5 & 9.1 & 225 \\
\hline $\mathrm{TiB}_{2}$ & 4.5 & $62 \times 10^{6}$ & 40,000 & 3.5 & 9.6 & 189 \\
\hline $\mathrm{ZrB}_{2}$ & 6.1 & $73 \times 10^{6}$ & 50,000 & 6.0 & 9.4 & 225 \\
\hline $\mathrm{ZrB}_{2}-\mathrm{B}$ & 5.4 & $30 \times 10^{6}$ & 65,000 & 15.0 & 17.6 & 328 \\
\hline $\mathrm{ZrB}_{2}-\mathrm{MoSi}_{2}$ & 5.2 & $70 \times 10^{6}$ & 25,000 & 1.1 & 5.3 & 115 \\
\hline $\mathrm{B}_{4} \mathrm{C}$ & 2.5 & $65 \times 10^{6}$ & 50,000 & 6.1 & 15.5 & 252 \\
\hline $\mathrm{VC}$ & 5.5 & $63 \times 10^{6}$ & 50,000 & 6.1 & 10.6 & 231 \\
\hline $\mathrm{BN}$ & 2.3 & $10 \times 10^{6}$ & 20,000 & 1.6 & 14.6 & 145 \\
\hline $\mathrm{Ta}_{2} \mathrm{Be}_{17}$ & 5.1 & $55 \times 10^{6}$ & 80,000 & 20.6 & 17.7 & 378 \\
\hline $\mathrm{BeO}$ & 3.0 & $58 \times 10^{6}$ & 45,000 & 4.8 & 13.4 & 225 \\
\hline $\mathrm{ZrO}_{2}$ & 5.8 & $35 \times 10^{6}$ & 35,000 & 3.0 & 9.5 & 172 \\
\hline $\mathrm{Si}_{3} \mathrm{~N}_{4}$ & 3.2 & $45 \times 10^{6}$ & 100,000 & 38.1 & 28.6 & 513 \\
\hline $\mathrm{SiC}$ & 3.1 & $70 \times 10^{6}$ & 80,000 & 19.5 & 20.7 & 389 \\
\hline $\mathrm{A}_{2}{ }_{2} \mathrm{O}_{3}$ & 4.0 & $55 \times 10^{6}$ & 100,000 & 36.0 & 24.2 & 486 \\
\hline Poco Graphite & 1.8 & $1.5 \times 10^{6}$ & 12,000 & 5.5 & 14.9 & 170 \\
\hline
\end{tabular}


The $R_{1}$ parameter gives rankings approaching $40 \mathrm{ft} / \mathrm{sec}$. The upper limit of the $R_{2}$ parameter is around $30 \mathrm{ft} / \mathrm{sec}$. In contrast, $R_{3}$ values up to $513 \mathrm{ft} / \mathrm{sec}$ (for $\mathrm{Si}_{3} \mathrm{~N}_{4}$ ) were calculated, which indicates that under ideal conditions impact velocities of interest to RTG applications may be possible. These conditions consist of adequate cushioning to prevent the $R_{1}$ type of fracture, and the ability to design and fabricate a fuel-containing ceramic shell that would have the same performance as a solid sphere made of the best of the candidate ceramics. Additional analytical study of the potential impact performance of solid ceramic spheres is described below. In this regard, consideration of the $R_{2}$ parameter indicates that a ceramic shel1 would have relatively poor impact performance under conditions where the fuel is loosely fit into the shell.

The most important material property affecting the order of the ranking of the materials is tensile strength. The two most outstanding materials in the ranking are $\mathrm{Si}_{3} \mathrm{~N}_{4}$ and $\mathrm{Al}_{2} \mathrm{O}_{3}$ which were the only two ceramics for which tensile strengths as high as 100,000 psi are given in Table 2 . For the materials listed in Table 2, low modulus values are associated with low tensile strengths. Thus, the benefit of low moduli for certain of the materials is offset by low tensile strengths.

Density differences between materials are not associated with strength, and lower density enhances impact performance. Lower density, of course, also is a benefit in reducing heat-source weight. On the basis of high strength and low density, silicon nitride $\left(\mathrm{Si}_{3} \mathrm{~N}_{4}\right)$ and silicon carbide (SiC) were judged to be the most promising of the listed ceramics.

\section{DETAILED ANALYSIS OF SILICON NITRIDE IMPACT MEMBER}

On the basis of the ranking-parameter screening of ceramic materials for impact performance, silicon nitride $\left(\mathrm{Si}_{3} \mathrm{~N}_{4}\right)$ was selected as the most promising of the high strength ceramics. Further efforts were directed to defining more precisely the velocity limitations of a $\mathrm{Si}_{3} \mathrm{~N}_{4}$ impact member. Also, the importance of such factors as shell thickness, loads imposed on the ceramic shell by the fuel, and elastic deformation of the target were 
investigated. These factors were studied using finite-element models of a spherical heat source. In this work the computer code HONDO as developed by Sandia Laboratories ${ }^{(5)}$ was applied to calculate transient stresses during the impact event.

\section{Effect of Shell Thickness}

Figure 5 shows the results of analysis of spherical impact shells of various wall thicknesses along with a solid sphere of $\mathrm{Si}_{3} \mathrm{~N}_{4}$. These results were generated using the quasi-static stress analysis and energy balance approach described above for the ranking parameter, $R_{2}$. For a hollow she11, the tensile bending stress decreases as the thickness of the she11 increases. As indicated, the tensile stress in the solid sphere is significantly less than that in the hollow spherical shells. The results of Figure 5 correspond to the $\mathrm{R}_{2}$ ranking parameter for hollow spheres and, as such, assume that local contact stresses at the point of impact are distributed by the presence of a layer of deformable material. In the case of the solid sphere, the tensile stress is internal rather than at a surface as in the hollow sphere. The results indicate that a cushioned solid $\mathrm{Si}_{3} \mathrm{~N}_{4}$ sphere could sustain an impact with a rigid target of nearly $200 \mathrm{ft} / \mathrm{sec}$ without fracture. Such an impact velocity is indicative of a monolithic heat source in which a strong ceramic fuel is integrally bonded within the ceramic impact she11. A dynamic stress analysis of such a heat source is described below. It is pointed out that a major developmental effort would be required in order to successfully fabricate such a monolithic heat source, particularly because of the problem in achieving a strong core-cladding bond and high strength in both components.

\section{Dynamic Versus Quasi-Static Analysis}

The initial derivation of the ranking parameter, $R_{2}$, and the curves of Figure 5 were based on application of energy methods to quasi-static type stress analyses. To check the validity of this approach, the structural 


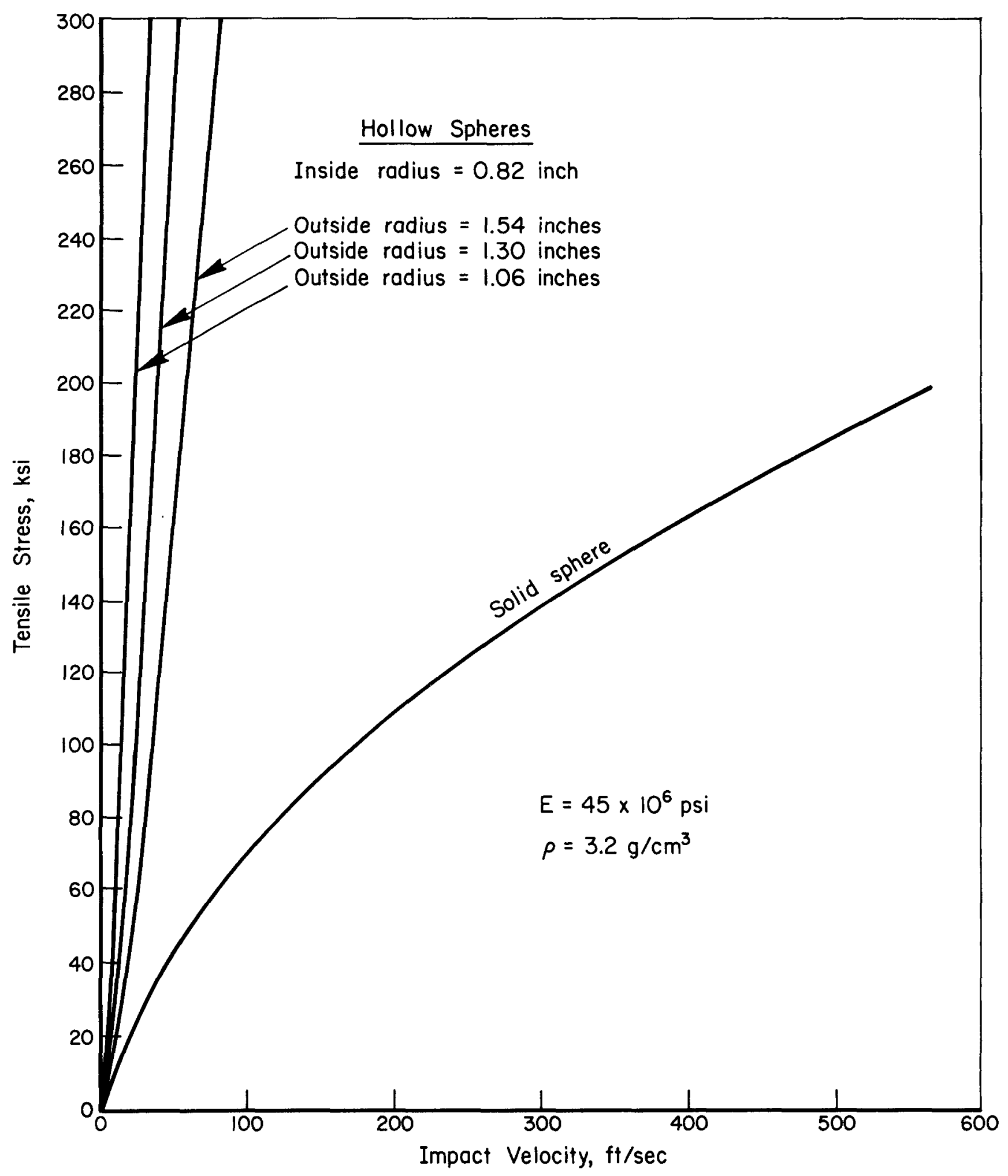

FIGURE 5. STRESS IN SILICON NITRIDE SPHERES WHEN IMPACTED AGAINST RIGID TARGET 
dynamics code HONDO has been applied to specific impact conditions for both solid and hollow sphere configurations. Results, shown in Figures 6 and 7 , indicate remarkable agreement between the static and dynamic stress distributions. The static solution forms an envelope to the peaks of the dynamic stress pattern at various times. As can be seen, the dynamic solutions show greater spatial variation in stress due to the presence of higher frequency modes of response. The static solutions approximate only the lowest frequency, or fundamental mode, which is of greatest interest. Figure 8 shows the time variation of deflection of the point on the back surface of the sphere. Very little difference in impact duration is present (approximately 60 microseconds, as indicated in Figure 8) between the hollow and solid sphere. The impact duration is also very nearly that (59.8 microseconds) estimated on the basis of contact stress theory as used for $R_{1}$ comparisons (Reference 4). This indicates that the duration of the impact event is governed primarily by the local deformation in the region of the sphere adjacent to the impact point.

\section{Effect of Target Deformation}

The ranking parameter, $R_{3}$, includes the effect of an elastic target (as opposed to a rigid target) on stresses in an impacting ceramic. Trends indicated by this parameter show that stresses for a granite target can be substantially less than stresses for an ideally rigid target. Therefore, it was believed that the stresses based on the rigid-target assumption are overestimated. A granite target (elastic modulus of $9 \times 10^{6}$ psi) is relatively compliant relative to $\mathrm{Si}_{3} \mathrm{~N}_{4}$ (elastic modulus of $45 \times 10^{6}$ ) and, thus, target deformations can significantly reduce impact member stress levels.

Figures 9 and 10 show the results of stress analyses performed with the HONDO computer code to evaluate the effect of impact taking into account elastic deformation of a granite target. The comparison is made for a solid $\mathrm{Si}_{3} \mathrm{~N}_{4}$ sphere impacting both a rigid and an elastic granite target at a velocity of $100 \mathrm{ft} / \mathrm{sec}$. It is seen that target deformations significantly 


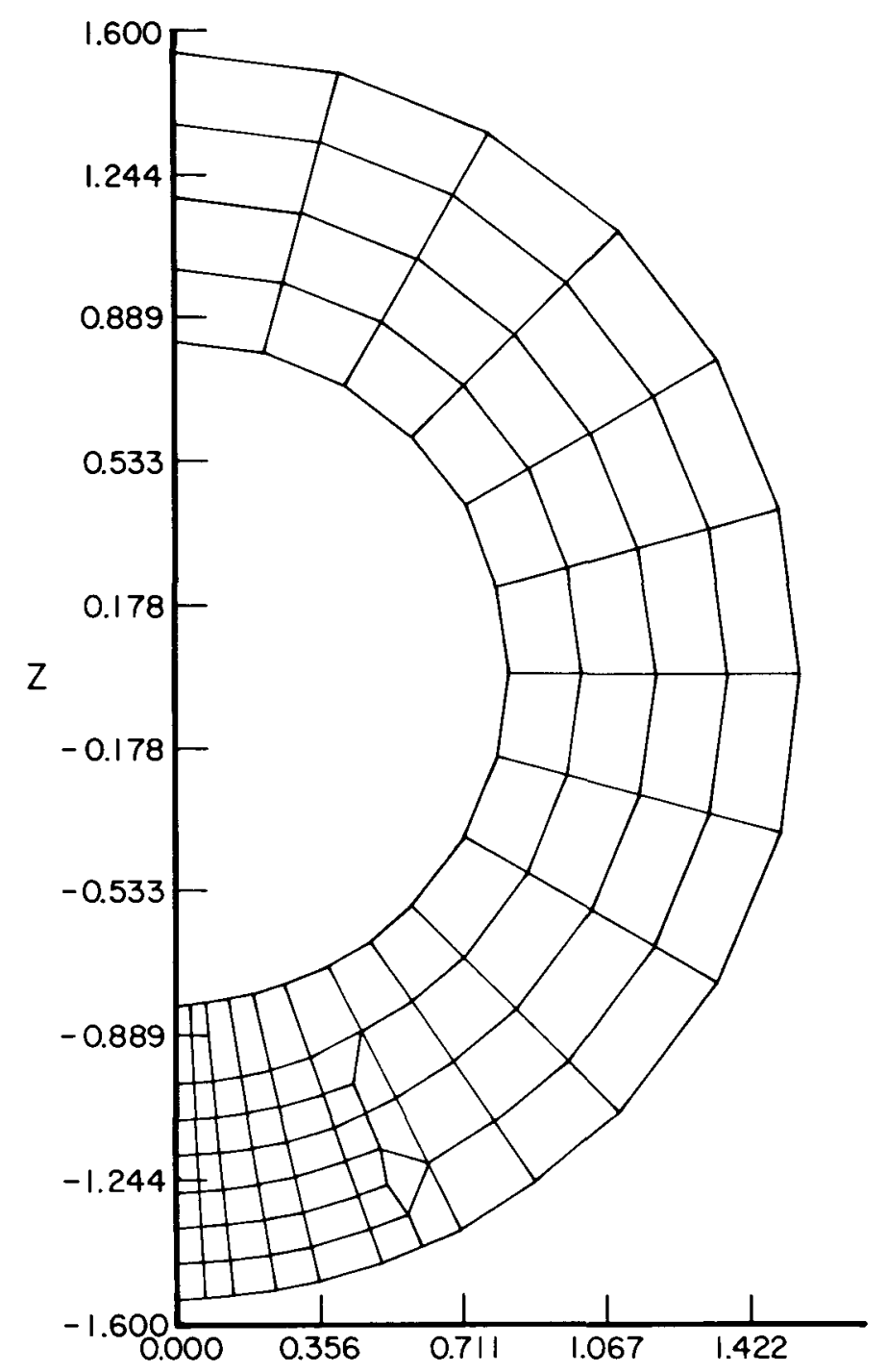

a. Finite-Element Model

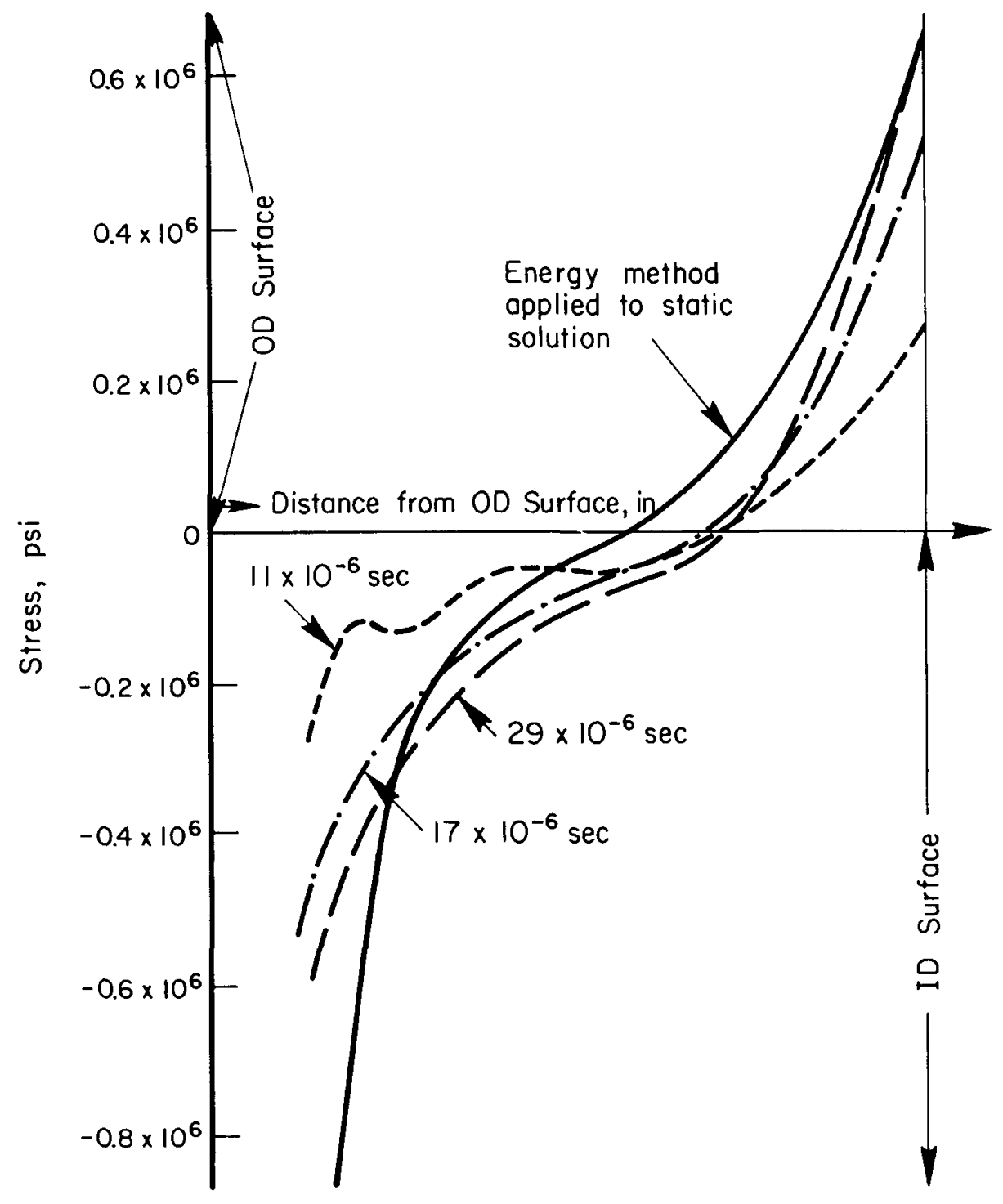

b. Calculated Stresses

FIGURE 6. STRESSES IN HOLLOW SILICON NITRIDE SPHERE AS CALCULATED BY COMPUTER CODE HONDO FOR IMPACT VELOCITY OF $100 \mathrm{FT} / \mathrm{SEC}$ 


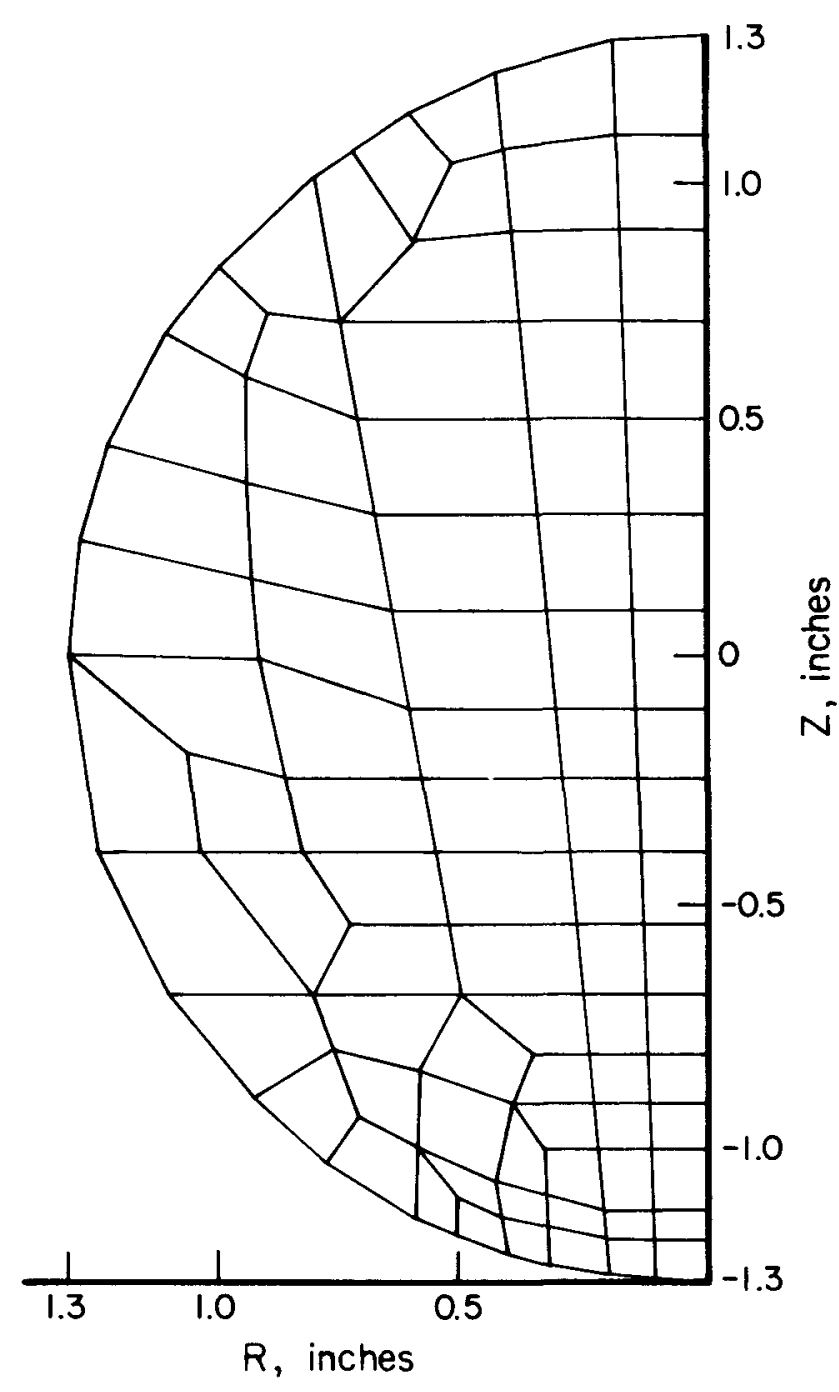

a. Finite-Element Model

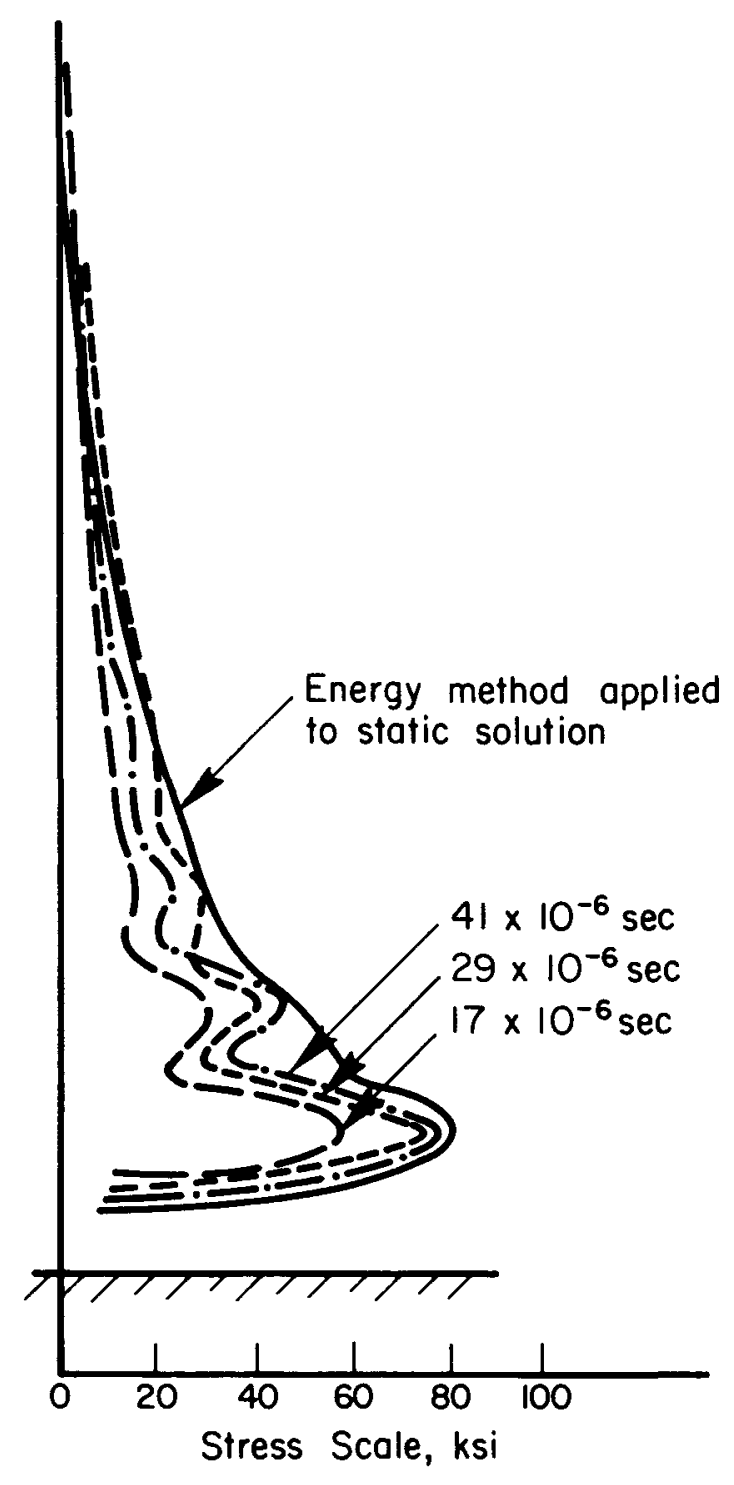

b. Calculated Stresses

FIGURE 7. STRESSES IN SOLID SILICON NITRIDE SPHERE AS CALCULATED BY COMPUTER CODE HONDO FOR IMPACT VELOCITY OF $100 \mathrm{FT} / \mathrm{SEC}$ 


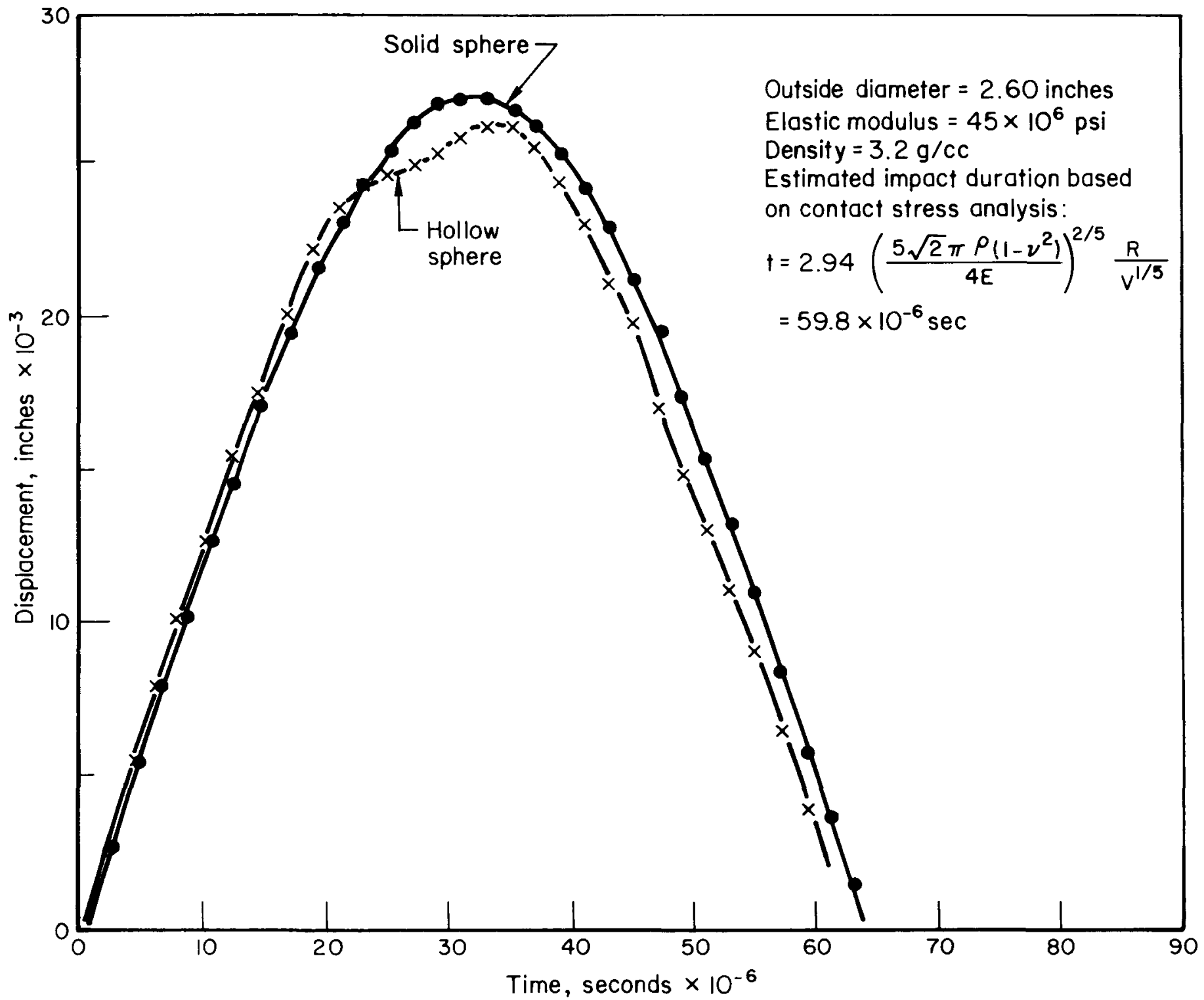

FIGURE 8. RESPONSE OF TRAILING SURFACE OF IMPACTING SILICON NITRIDE SPHERE AS CALCULATED BY COMPUTER CODE HONDO FOR IMPACT VELOCITY OF $100 \mathrm{FT} / \mathrm{SEC}$ 


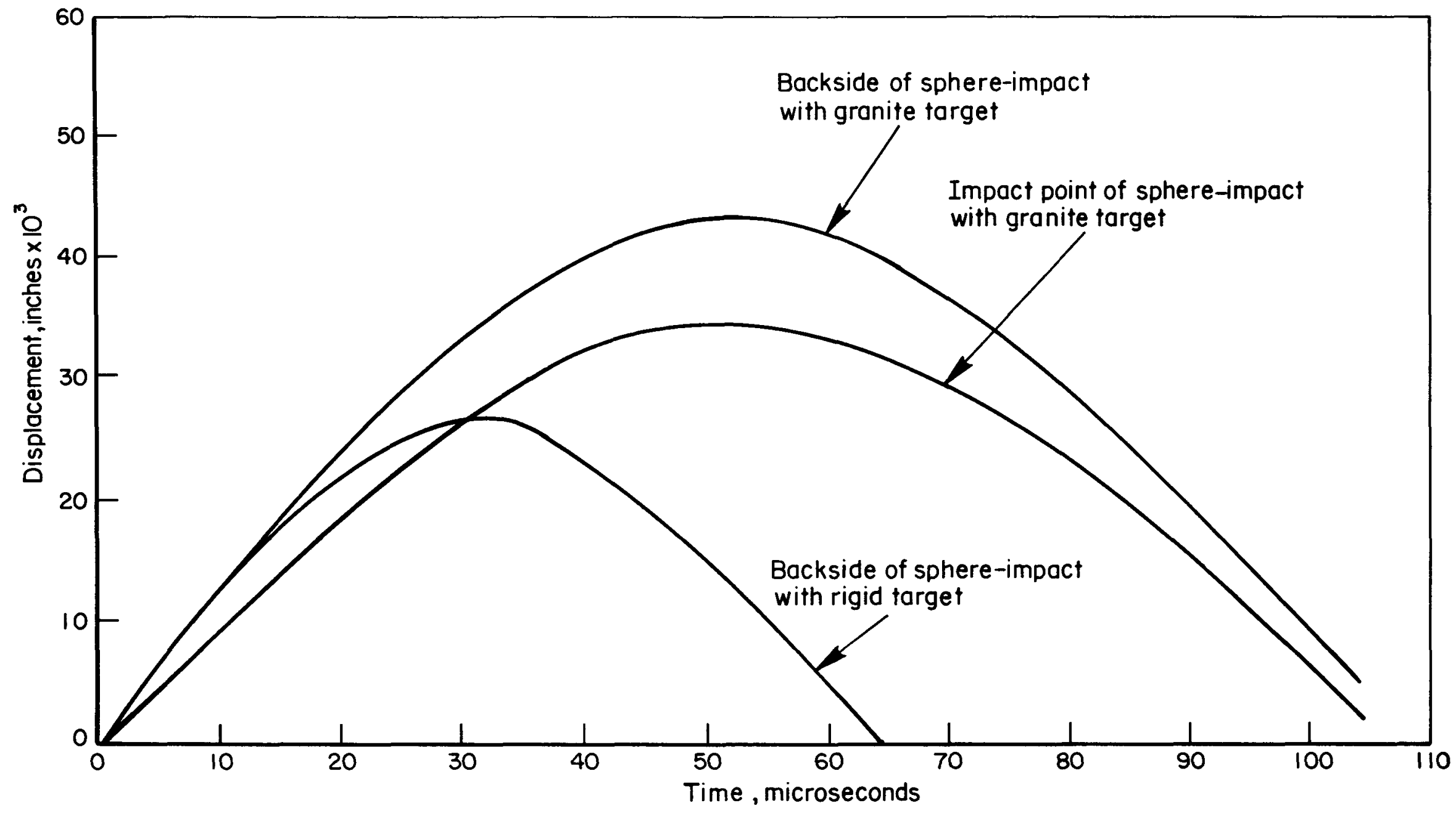

FIGURE 9. EFFECT OF TARGET DEFORMATION ON IMPACT RESPONSE OF A SOLID SILICON NITRIDE SPHERE AS CALCULATED BY COMPUTER CODE HONDO FOR IMPACT VELOCITY OF $100 \mathrm{FT} / \mathrm{SEC}$ 


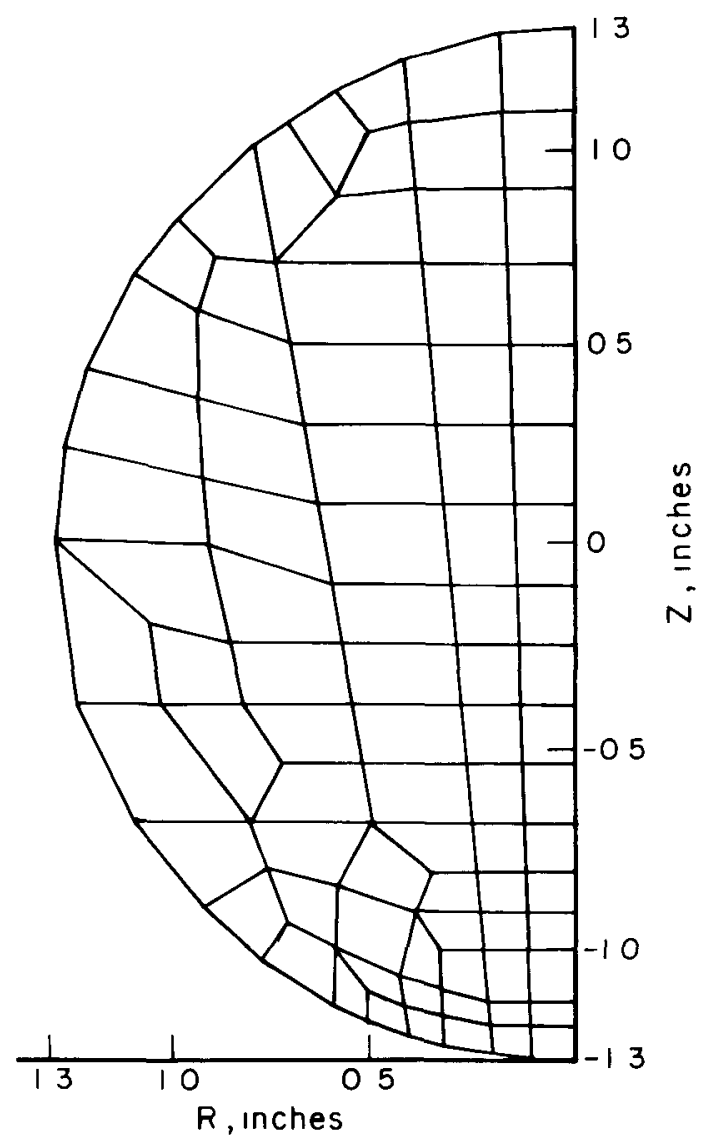

a Finite-Element Model

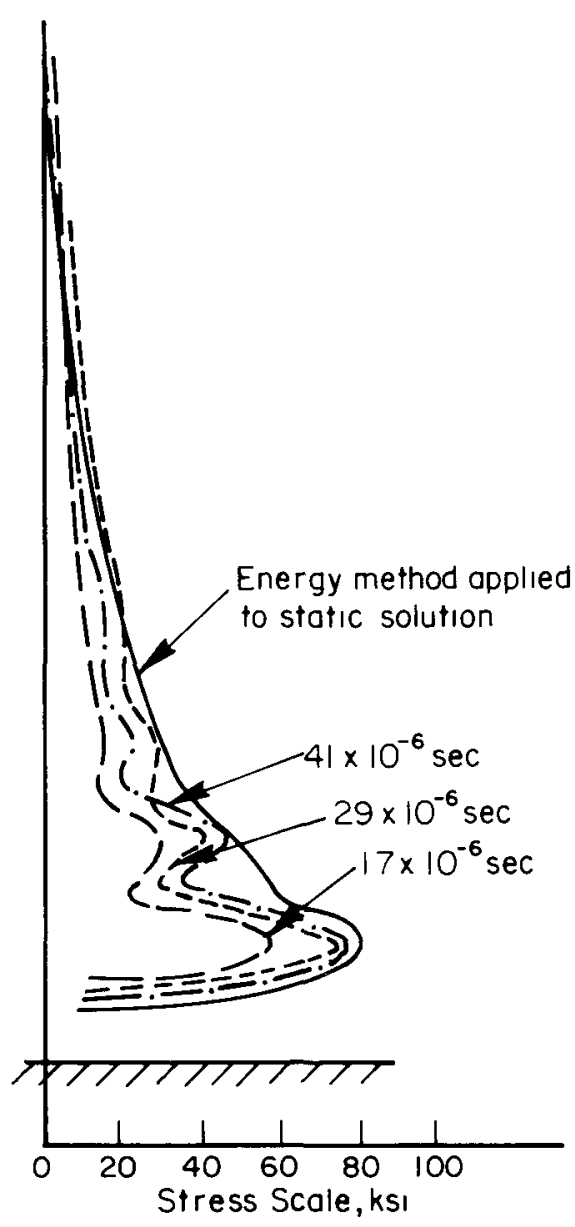

b Calculated Stresses For Rigid Target

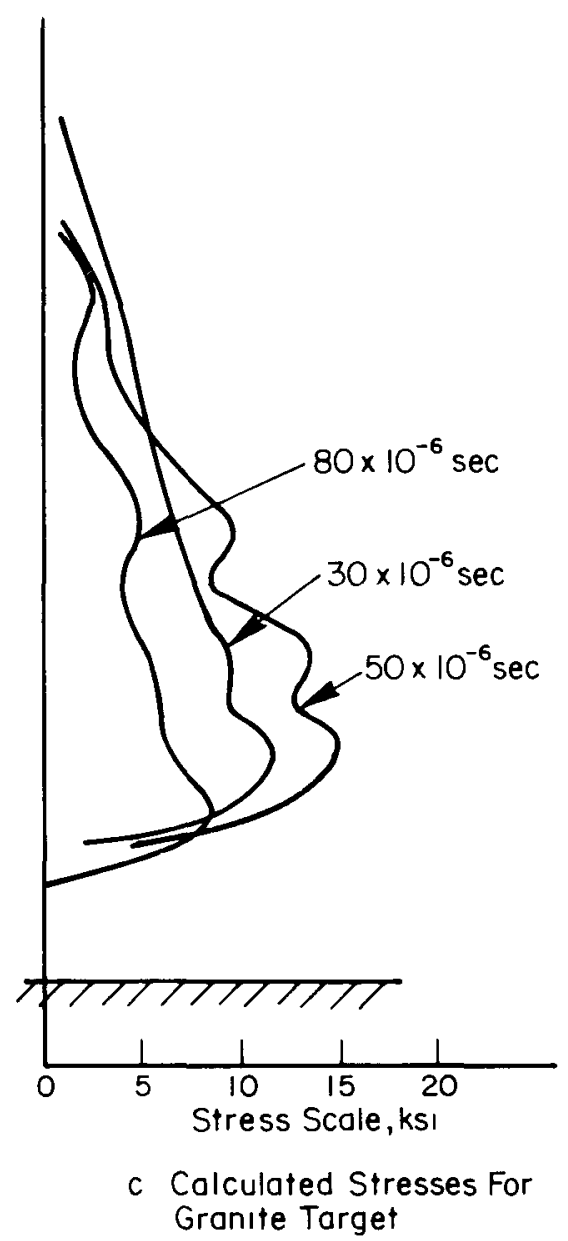

FIGURE 10. STRESSES IN SOLID SILICON NITRIDE SPHERE AS CALCULATED BY COMPUTER CODE HONDO FOR IMPACT VELOCITY OF $100 \mathrm{FT} / \mathrm{SEC}$, SHOWING EFFECT OF TARGET DEFORMATION 
reduce the maximum stresses in the $\mathrm{Si}_{3} \mathrm{~N}_{4}$, with the reduction being from about 80,000 psi to about $15,000 \mathrm{psi}$. This result shows that the target response will significantly effect the occurrence of fracture of the ceramic during impact. Therefore, in evaluating impact response of ceramics, careful consideration should be given to the target material. In the analyses reported here, the granite was assumed to respond in an elastic manner without fracturing. In an actual impact situation, local fracturing at the impact point in the granite target is certain to occur if the impacting material is as hard and strong as $\mathrm{Si}_{3} \mathrm{~N}_{4}$. The energy absorption associated with fracturing of the target (cracking and local crushing of the granite) has not been taken into account, and probably cannot be treated satisfactorily on an analytical basis. Since the tensile strength of granite is on the order of 10 to 20 times less than that of $\mathrm{Si}_{3} \mathrm{~N}_{4}$, it is believed that fracturing as we11 as elastic deformation will result in reduced stress levels in the impacting ceramic. This effect will probably be more important to the $R_{1}$ type of contact stress than the $R_{2}$ type of bending stress. Results reported below for stresses in hollow ceramic shells show $R_{2}$ type of stress levels to be relatively less sensitive to target response (reduction in stress by a factor of about two rather than about five).

\section{Effect of Fuel}

In development of the ranking parameters and in the analytical screening of high strength ceramics, the presence of the fuel was neglected, except for the parameter $R_{1}$ where the fuel was factored into the overall heat source mass. Within present RTG systems, the bulk mechanical properties of the fuel are still being determined, and they are not well-controlled. There is also a considerable variation in microstructure and properties, core to surface, indicating variation in mechanical properties of the fuel. Thus, there is no "standard" fuel which can be used for the ranking procedure. Also, consideration of the fuel would have made derivation of simple ranking parameters very difficult. In the final analysis, it is not believed that the intrinsic properties of the fuel will affect the preceding relative 
rankings of the ceramic materials. The fuel, however, will affect the absolute values of the estimated impact-velocity capabilities. Therefore, analyses were conducted on the basis of assumed behavior of both "weak" and "strong" ceramic fuels.

Figure 11 shows the effect on stress levels of the presence of a weak or yielding $\mathrm{PuO}_{2}$ fuel within a hollow $\mathrm{Si}_{3} \mathrm{~N}_{4}$ impact shell. A rigid target and an impact velocity of $100 \mathrm{ft} / \mathrm{sec}$ were selected for this comparison. An elastic-plastic behavior and an elastic modulus of $25 \times 10^{6}$ psi and a yield strength of 10,000 psi were assumed for the fuel. It was assumed that no bond existed between the fuel and the $\mathrm{Si}_{3} \mathrm{~N}_{4}$ shell. The interface between the fuel and impact shell was permitted to support compressive stresses, but not tensile or shear stresses. The bending stresses in the shell were found to be slightly reduced from those calculated for the empty shell (Figure 11b). Hoop stresses were found to be at a higher level in the impact she1l containing fue1. This was due to pressure imposed on the inside of the shell by the decelerating fuel. However, these hoop stresses were much lower in magnitude than the bending type of stresses shown in Figure 11c.

Figure 12 shows the finite-element model developed for analyzing stresses in a $\mathrm{Si}_{3} \mathrm{~N}_{4}$ shell with fuel for impact with a large granite target. This model was used in analyses using the HONDO finite-element code. Results of calculations for a strong (or unyielding) fuel are shown in Figure 13 for comparison with the results shown in Figure 14 for a weak (or yielding) fuel. For the strong fuel, an elastic modulus of $25 \times 10^{6}$ psi was used, and it was assumed that a bond existed between fuel and the $\mathrm{Si}_{3} \mathrm{~N}_{4}$ shell. At the selected impact velocity of $100 \mathrm{ft} / \mathrm{sec}$, the strong fuel gave a maximum stress of about 40,000 psi in the impact she11, which was much less than the maximum stress of about 325,000 psi in the shel1 for the weak-fuel assumption. Since the attainable tensile strength of $\mathrm{Si}_{3} \mathrm{~N}_{4}$ can be as high as $100,000 \mathrm{psi}$, the she11 with a strong bonded fuel could withstand a $100 \mathrm{ft} / \mathrm{sec}$ impact, provided that the local stresses at the impact point were suitably distributed to prevent local fracture at the impact point. The shell with the weak, unbonded fuel would certainly fracture if impacted at $100 \mathrm{ft} / \mathrm{sec}$. Hoop-stress levels for the weak fuel case are shown in Figure 15. Near the impact point the hoop stresses are the same as the local stresses shown in Figure 14. At the 

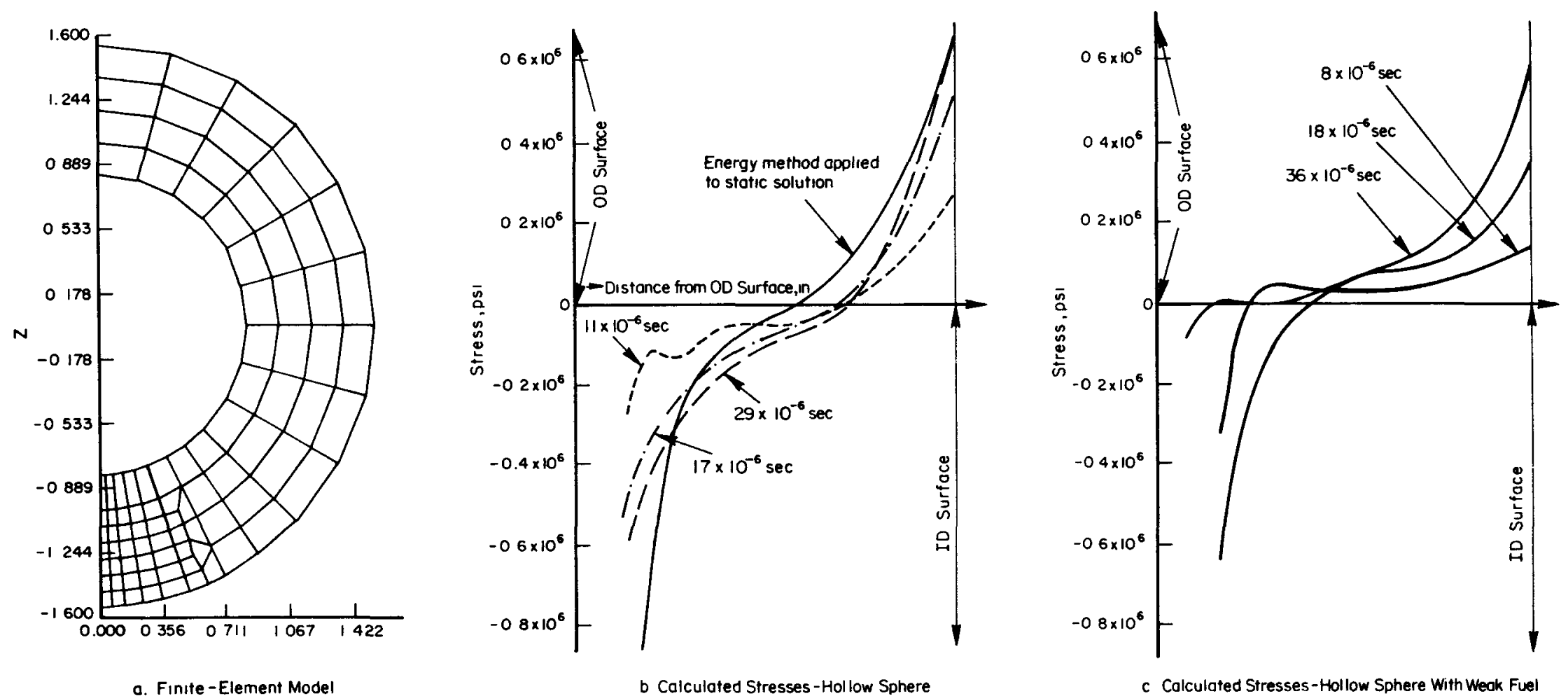

FIGURE 11. STRESSES IN HOLLOW SILICON NITRIDE SPHERE AS CALCULATED BY COMPUTER CODE HONDO FOR IMPACT VELOCITY OF $100 \mathrm{FT} /$ SEC ONTON RIGID TARGET, SHOWING EFFECT OF FUEL WITHIN SPHERE 


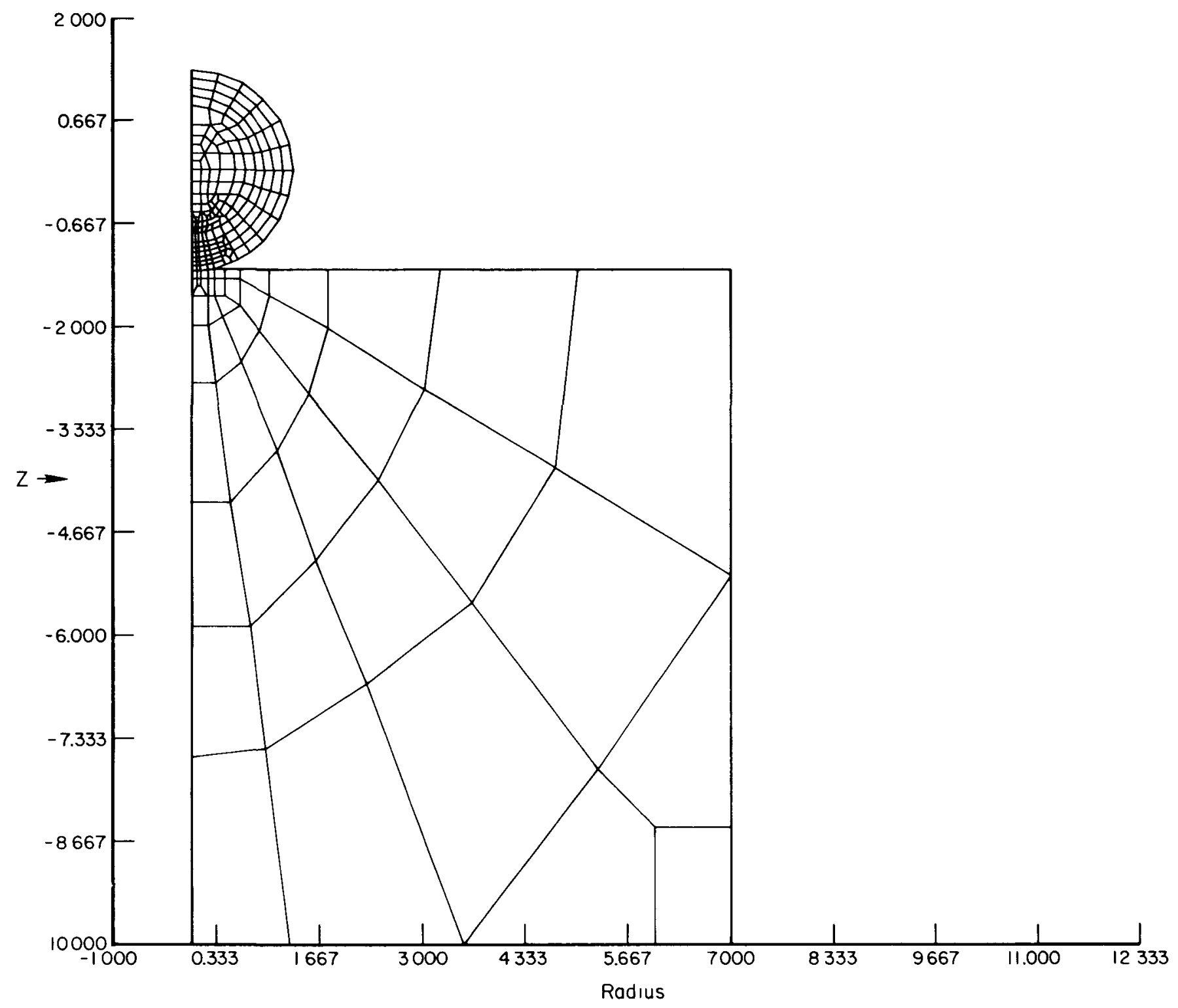

FIGURE 12. FINITE-ELEMENT MODEL OF HOLLOW SILICON NITRIDE SPHERE WITH FUEL FOR ANALYSIS OF IMPACT WITH GRANITE TARGET 


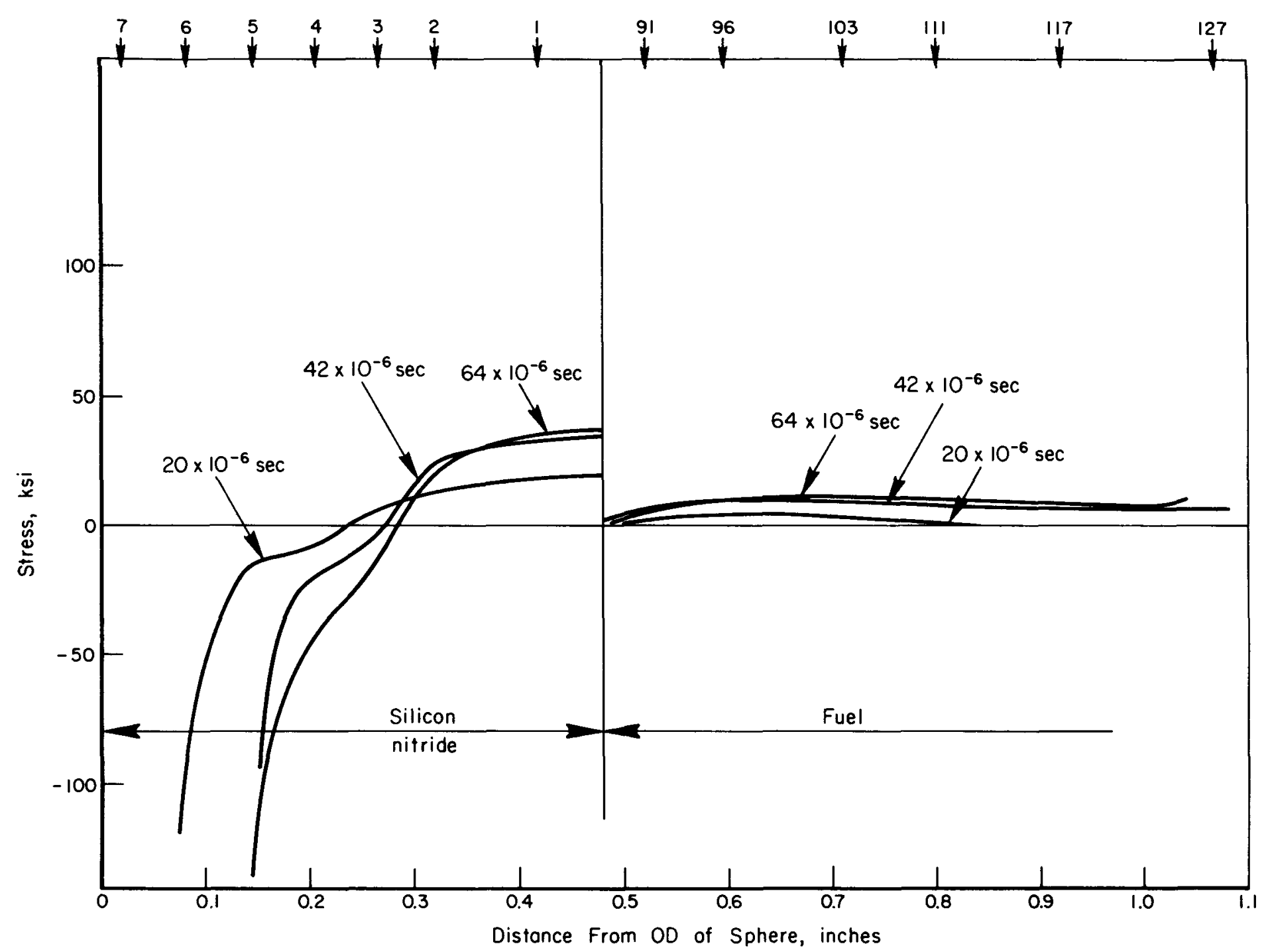

FIGURE 13. CALCULATED STRESSES FROM HONDO FOR 100 FT/SEC IMPACT OF HOLLOW SILICON NITRIDE SPHERE WITH GRANITE TARGET: FUEL ASSUMED TO BE STRONG (UNYIELDING) AND BONDED TO SILICON NITRIDE 


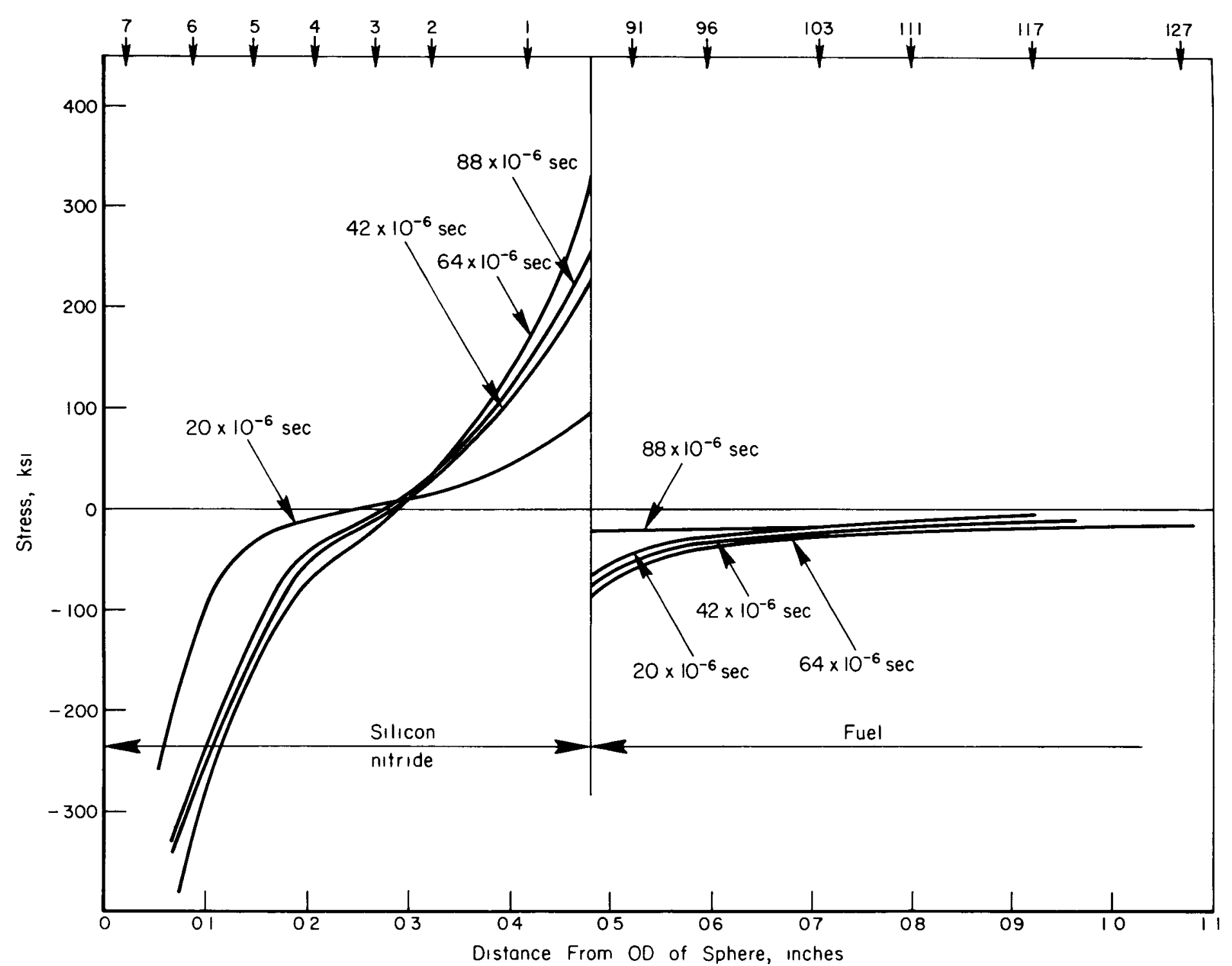

FIGURE 14. CALCULATED STRESSES FROM HONDO FOR $100 \mathrm{FT} / \mathrm{SEC}$ IMPACT OF HOLLOW SILICON NITRIDE SPHERE WITH GRANITE TARGET: FUEL ASSUMED TO BE WEAK (YIELDING) AND BONDED TO SILICON NITRIDE 


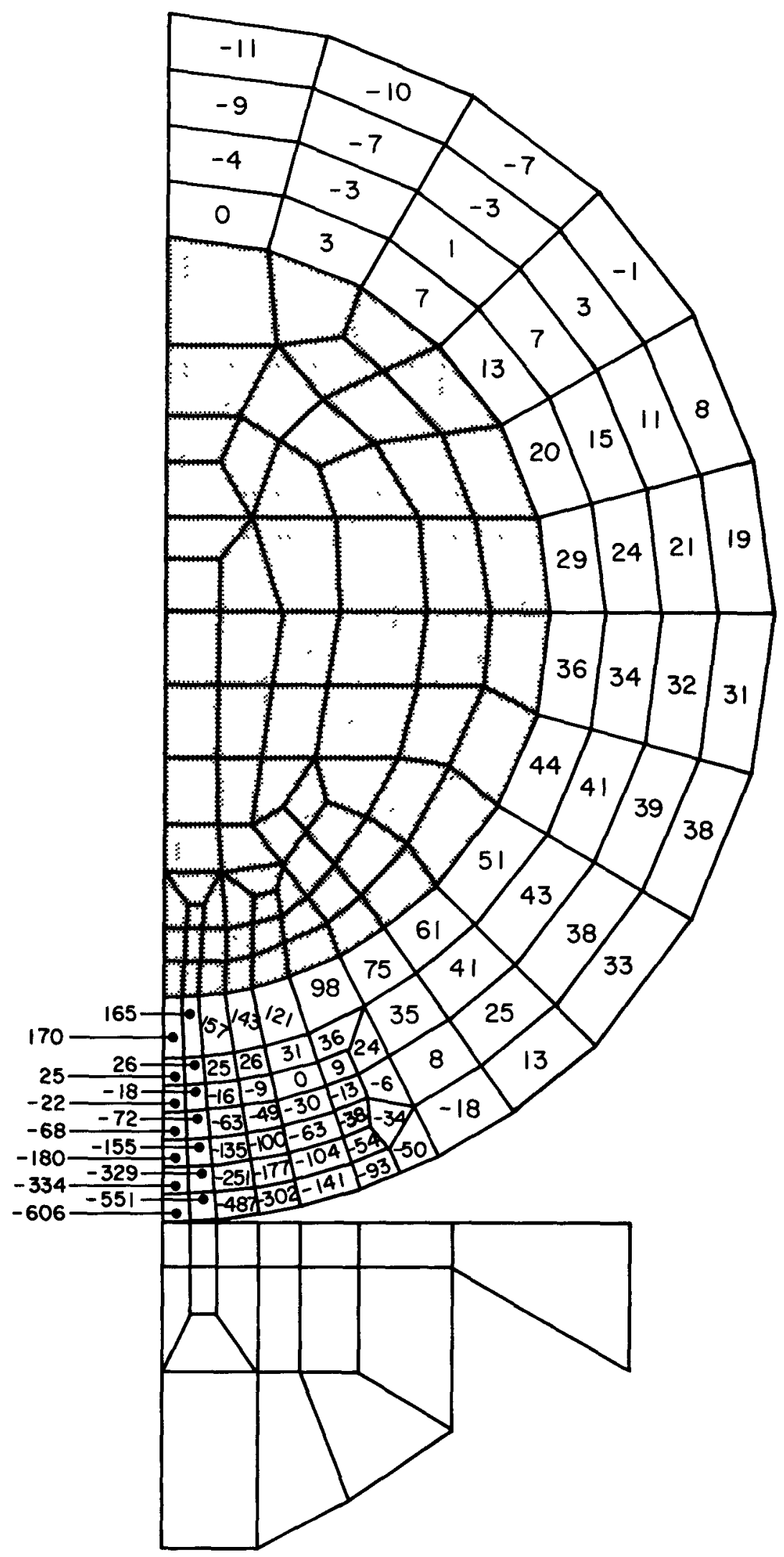

FIGURE 15. CALCULATED HOOP STRESSES IN SILICON NITRIDE SPHERE AT $64 \times 10^{-6}$ SEC FOR 100 FT/SEC IMPACT WITH GRANITE TARGET: FUEL ASSUMED TO BE WEAK (YIELDING) AND NOT BONDED TO SILICON NITRIDE 
diameter (90 degrees from the impact point), the hoop stress has a magnitude of about 30,000 to $40,000 \mathrm{psi}$, and is much less than the maximum tensile stresses nearer the impact point. Thus, diametrical hoop stresses due to pressures imposed by the fuel on the $\mathrm{Si}_{3} \mathrm{~N}_{4}$ shell will not govern fracture for the she11 thickness considered.

\section{FABRICATION CONSIDERATIONS FOR CERAMIC IMPACT MEMBER}

In the fabrication of fueled modules that comprise a heat source and use a ceramic impact containment member, a number of severe problems would be encountered. The foremost among these is the problem of fuel strength. In order to achieve impact velocities of practical interest, the fuel must be mechanically bonded to the ceramic impact shell so that the assembly will respond in impact as a monolith. In this connection, the strength of the fuel and that of the bond must be comparable to those of high strength ceramics. Present-day ceramic ${ }^{238} \mathrm{PuO}_{2}$ fuels have been shown to have relatively low strengths, and enhancement of these strengths would probably require a rather extensive developmental effort. In particular, the ${ }^{238} \mathrm{PuO}_{2}$ feed material contains a variety of impurities in quantities that would make the achievement of good mechanical strengths difficult. The removal of the impurities through modification of the production process for the ${ }^{238} \mathrm{PuO}_{2}$ raw material would be both a significant and a costly effort. A second problem encountered with the ${ }^{238} \mathrm{PuO}_{2}$ fuel is the release of helium gas from radioactive decay processes. This gas is evolved within the structure of the material, and must be released from the material without degrading its strength. The mechanisms by which the helium gas is stored within the material structure and eventually released are not well understood. It is known, however, that at ${ }^{238} \mathrm{PuO}_{2}$ densities in excess of 95 percent of theoretica1, where maximum strength would be attained, the tight structure impedes helium release. The degradation of mechanical properties of ${ }^{238} \mathrm{PuO}_{2}$ with time (aging) is embryonic in technical understanding but is significant.

A second strength-associated manufacturing problem is in the bonding of the fuel to a dissimilar ceramic shell, the desirability of which has been 
previously discussed. Bonds of this type have been achieved in the case of other ceramic systems. Considerable developmental effort can be expected before a set of process parameters for bonding can be specified, even with assurance that ${ }^{238} \mathrm{PuO}_{2}$ is compatible for bonding purposes with any of the high strength ceramics of interest.

Possibly the greatest problem in bonding ${ }^{238} \mathrm{PuO}_{2}$ with a high strength ceramic shell would be that of the thermal-expansion mismatch. In processing, during fabrication, and during subsequent operation of the heat source, thermal histories will be imposed. Unless the thermal-expansion coefficients of the fuel and ceramic impact member are very closely matched, differential expansions of the dissimilar materials will result in severe thermal stresses and fracturing of one or the other of the materials. Precise thermal-expansion coefficient data for ${ }^{238} \mathrm{PuO}_{2}$ typical of RTG usage are now available ${ }^{(6)}$, and the expansion is high relative to the ceramics of interest to the impact application.

The fabrication and production of shapes of interest to heat source applications also present problems. Uniaxial hot pressing of a ceramic into a spherical shape with a unfform and homogeneous microstructure is not possible. One might first form hemispheres and then bond the hemispheres. This is not a simple operation, and bonding the fuel into the assembly would only further complicate the operation.

A number of design problems will be encountered with a ceramic member, one of which will be the provision of a vent, if required, to allow the release of helium gas through the impact-containment member. The introduction of any penetration through the ceramic material will result in stress concentrations which will degrade the impact performance of the ceramic member. It is, on the other hand, concelvable that the ceramic impact structural member could be tallored in its porosity to permit helium release directly through the shell. However, this is not an attractive prospect due to the decrease in strength associated with porosity. Another unlikely possibility, which would be fortuitous, is that the selected ceramic might be naturally permeable to helium, even at high density.

The design and assembly of heat sources are complicated by the difficulties present in handling of the ${ }^{238} \mathrm{PuO}_{2}$ fuel. The fuel is both heat-emitting and radioactive and must be handled with great care for safety 
reasons. Thus, many otherwise routine fabrication and assembly operations must be performed remotely and under conditions of isolation. Even after these operations, the final assembled item must be completely cleared of transferable surface radioactivity prior to incorporation into the RTG.

\section{STRUCTURAL DESIGNING WITH CERAMIC MATERIALS}

In the analyses in this report, the strength of each candidate ceramic was assumed to be a deterministic property of the material. Although this assumption is acceptable as a basis for comparing and screening the candidates for impact-member service, it oversimplifies the actual situation and should not be used without qualification in designing an actual ceramic impact member. In designing with ceramic materials, gross safety factors are often imposed to assure a low probability of failure under service stresses. In high-performance hardware such as heat sources, the weight penalties imposed by such a traditional design approach are prohibitive. This section of the report is intended to describe the variations and trends in strengths of ceramics that have been observed in well-controlled strength tests. The data and discussion provide insight into the strength levels which are appropriate for use in the design of a ceramic impact member for a heat source.

According to present knowledge of brittle behavior, strength is controlled by crack genesis at the most-severe defect in a specimen or component under tension, and the severity and density of defects in the material are statistically distributed. Further, no mechanism operates in these materials to arrest the crack once it is initiated. Strength, therefore, is probabilistic in nature rather than deterministic, and one should, in a strict sense, define strength in terms of the probability of fracture at any stress. A ceramic's strength as usually reported is a 50 percent probability of failure. However, most structural designs, and certainly the design of an isotopic heat source impact member, require that stresses be maintained at levels to assure near-zero probability of failure. 
The degree of concern about the probabilistic nature of strength of a ceramic material, of course, depends on the extent that its strength values are dispersed, and this is highly dependent on the specific material and on processing methods and controls used in producing the ceramic piece. Strength dispersions also are extremely difficult to define in a usable way for structural design purposes. As indicative of the latter problem, consider the probability of failure (P) versus stress $(\sigma)$ curves in Figure 16 for a relatively high strength, high quality ceramic which were generated in recent research at Battelle ${ }^{(7)}$. Highly defined and controlled strength tests were conducted at room temperature on specimens of three sizes in two environments ("wet", or immersed in water, and "dry", or in dry nitrogen gas) to obtain the six P- $\sigma$ curves shown. As can be seen, these curves reasonably define the stress for failure probabilities between 0.1 and 0.9 , and show that the stress for any probability in this range depends on the ambient and on specimen size. More important, these two testing variables also affected the basic nature of the $P-\sigma$ relationship. Investigation into this latter finding showed that defects of different types were operative in the material, and the nature of the $\mathrm{P}-\sigma$ relationship depended on which type(s) controlled fractures in that particular test. Unless the strength-controlling defects in all tests arefrom a single statistical population, one cannot apply statistical mathematics to the problem of seeking correlations between strength data from the different tests.

of possibly greater significance, P- $\sigma$ curves require extrapolation to obtain the stress for which the probability of failure is near zero, i.e., to obtain the stress value that is needed for structural designing of a heat source impact member. To provide a sound basis for such an extrapolation, one needs to know rather exactly the nature of the relationship in the region from 0.1 to zero probability. No practical means for obtaining this knowledge is at hand. An improved definition of the $P-\sigma$ relationship in the low- $P$ region could be acquired, of course, simply by testing a greater number of specimens than the maximum of 25 used to obtain the curves in Figure 16, but this approach, even with tests of hundreds of specimens, fails to provide a fundamental basis for the empirical relationship, hence the needed assurance that the low-probability end of the curve is adequately defined. 


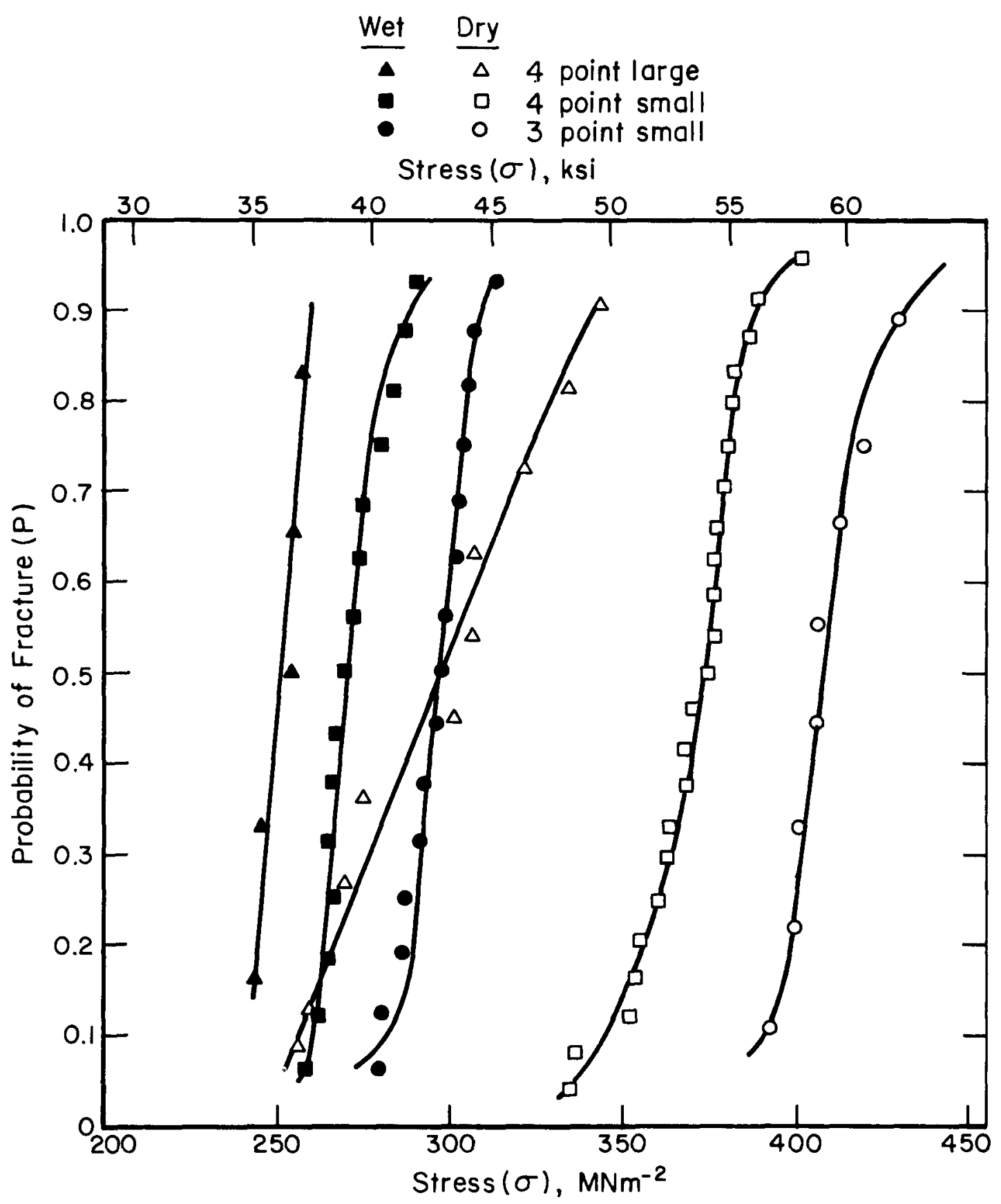

FIGURE 16. FAILURE PROBABILITY CURVES FOR AN $\mathrm{Al}_{2} \mathrm{O}_{3}$ CERAMIC 
Better approaches appear to be avallable for establishing a stress level that can be used in structural designing of ceramic components. However, no approach has yet been the subject of sufficient research for proven utility through a reduction to practice.

In one approach, the variability in strength is reduced to an insignificant level through a combination of material-development efforts, fractographic studies of strength-controlling defects in the material, extensive testing, and development of nondestructive-testing procedures for the material. Referring to Figure 16, for example, defects from the population which controlled strengths in the case of the curve represented by open triangles were much more severe (and more sparsely distributed) than those which controlled strengths of the other specimens. Processing refinements or other measures that could assure elimination of the open-triangle type of defects would go a long way toward removing the troublesome strength variability in this particular ceramic.

The other approach is that of proof testing. The concept is simply to stress the specimens or components to a predetermined level and reject those that fail. If the remainder are subsequently tested to failure, the $P-\sigma$ curve which results is truncated, and the troublesome low-probability end of the curve is eliminated--the stress corresponding to zero probability being completely known. The selection of the proof-test level determines the maximum design stress (i.e., the strength), and it also determines the number of pieces that will be rejected. A report on the proof-testing concept has recently been issued ${ }^{(8)}$, and among other matters treated, it indicates that the nature of the applied loading in the proof test need not reproduce the operational stress distribution. Methods are available to permit the use of any convenient proof test regardless of stress distributions encountered in service.

In summary, should SNS undertake the development of a ceramic impact member in the next few years, coincident with that development would be the need to extend the state of the art in structural designing with brittle materials. No established design technique is available at present to permit assigning levels of impact loading that would reasonably assure freedom from failure. 


\section{CONCLUSIONS AND RECOMMENDATIONS}

The major conclusion of Battelle's study is that present-day structural ceramic materials have little potential for use as the impact member in isotopic heat source applications. Of the available high strength ceramics, silicon nitride offers the most promise followed by silicon carbide and aluminum oxide, and the extensive stress analyses reported here show severe limitations on allowable velocities for impact with granite following reentry for these ceramics. Impact velocities in the 100 to $200 \mathrm{fps}$ regime can be achieved only by the addition of an additional layer to distribute the high contact stress. Besides impact limitations, application of ceramic materials in heat sources would present problems both in terms of weight and fabrication. The required thickness of a ceramic impact member would be comparable to that for a carbon-carbon composite material. However, the least dense of the high strength ceramics are 2 to 3 times more dense than the carbon-carbon composites. Fabrication of a ceramic heat source would require a high strength bond between the fuel and the impact member if reasonable impact velocities are to be achieved. Formation of such a bond in ceramic materials is a difficult task under normal circumstances, and would be more difficult under the restrictions imposed on the processing and handling of the ${ }^{238} \mathrm{PuO}_{2}$ fuel.

It is recommended that ceramic materials be given low priority by SNS for future heat source applications. The low probability of successful application of any ceramic does not justify significant research efforts at this time. The techniques developed by Battelle do, however, provide a means to assess the potential of improved ceramics that may appear in the future. 


\section{REFERENCES}

(1) Simonen, F. A., Bansal, G. K., and Duckworth, W. H., "RTG Impact Member Materials: A Preliminary Technical Review", submitted to Space Nuclear Systems Division by Battelle's Columbus Laboratories (June 30, 1975).

(2) "SNAP-19 Viking Final Safety Analysis Report, Volume I, Reference Design Document", to U.S. Atomic Energy Commission by Teledyne Isotopes, Inc., ESD-3069-15-1 (August, 1975).

(3) "Multi-Hundred-Watt Radioisotope Thermoelectric Generator Program, Volume 1 - Reference Design Document for LES 8/9", to U.S. Atomic Energy Commission by General Electric's Space Division (July, 1972).

(4) Timoshenko, S., and Goodier, J. N., Theory of Elasticity, McGraw-Hill, New York (1951).

(5) Key, S. W., "HONDO - A Finite-Element Computer Program for the Large Deformation Dynamic Response of Axisymmetric Solids", SLA-74-0039, by Sandia Laboratories for U.S. Atomic Energy Commission (April, 1974); modified in June, 1975.

(6) Kent, R. A., Los Alamos Scientific Laboratory, LA-6232-MS (February, 1976).

(7) Bansa1, G. K., Duckworth, W. H., and Niesz, D. E., "Strength-Size Relationships in Ceramic Materials", Battelle's Columbus Laboratories, Technical Report No. 4, Office of Naval Research, Contract No. N00014-73-C-0408 (October, 1975).

(8) "Structura1 Ceramics", Committee on Structural Ceramics, National Academy of Sciences, Report NMAB-320 (1975). 
Division of Nuclear Research and Applications

Energy Research and Development Administration

washington, D.C. 20545

D. C. Bauer

R. T. Carpenter

T. Dillon

G. P. Dix

T. J. Dobry

M. I. Farfel

N. Goldenberg

W. D. Kenney

A. P. Litman (10)

J. J. Lombardo

A. L. Mowery

G. A. Newby

B. J. Rock

C. O. Tarr

N. R. Thielke

E. J. Wahlquist

Division of Reactor Development and Demonstration

Energy Research and Development Administration Washington, D. C. 20545

J. M. Simmons

Division of Physical Research Energy Research and Development Administration

Washington, D. C. 20545

D. K. Stevens

AiResearch Manufacturing Company of Arizona

402 South 36 th street

P. O. Box 5217

Phoenix, Arizona 85010

J. R. Hadley

J. E. McCormick
Fairchild space and Electronics Company

Germantown, Maryland 20767

M. Eck

A. Schock

General Atomic Company

P. O. Box 608

San Diego, California 92112

N. E1sner

General Electric Company Valley Forge Space Center P. O. Box 8048

Philadelphia, Pennsylvania 19101

E. W. Williams

Los Alamos Scientific Laboratory P. O. Box 1663

Los Alamos, New Mexico 87545

R. D. Baker

S. E. Bronisz

S. Hecker

R. A. Kent

R. N. R. Mulford

Minnesota Mining and Manufacturing Company

2501 Hudson Road

St. Paul, Minnesota 55119

E. F. Hamp1

Monsanto Research Corporation P. O. Box 32

Miamisburg, Ohio 45342

W. T. Cave/D. P. Ke11y

E. W. Johnson/D. L. Coffey

NASA Jet Propulsion Laboratory California Institute of Technology 4800 Oak Grove Drive Pasadena, California 91103

V. Trusce110 
NASA Lewis Research Center 2100 Brookpark Road

Cleveland, Ohio 44135

M. Ault

P. Kerwin

R. H. Titran

Air Force Weapons Laboratory Kirtland Air Force Base

Albuquerque, New Mexico

Attn: Capt. E. W. Holtzscheiter

Attn: Col. W. K. Hillyer

Oak Ridge National Laboratory P. O. Box X

Oak Ridge, Tennessee 37830

H. Inouye

R. Kennedy

E. Lamb

A. C. Schaffhauser (2)

J. R. Weir, Jr.

Oak Ridge National Laboratory Y-12 Plant

P. O. BoX $Y$

Oak Ridge, Tennessee 37830

C. Pollock

Savannah River Laboratory

E. I. DuPont de Nemours \& Company

Aiken, South Carolina 29801
R. Gregg
R. T. Huntoon
R. McDonnel1

Savannah River Operations office Energy Research and Development Administration

P. O. Box "A"

Aiken, South Carolina 29801

L. M. East
Sunstrand Energy Systems

4747 Harrison Avenue

Rockford, Illinois 61101

E. Kreuger

Teledyne Energy Systems

$110 \mathrm{~W}$. Timonium Road

Timonium, Maryland 21093

W. J. Barnett

G. Linkous

W. Osmeyer

Technical Information Center

Energy Research and Development Administration

Office of Information Services

P. O. Box 62

Oak Ridge, Tennessee 38930

Battelle

Pacific Northwest Laboratories

Battelle Boulevard

Richland, Washington 99352

J. Jarrett

F. A. Simonen

\section{Internal Distribution}

W. H. Duckworth (3)

F. L. Bagby

G. K. Bansal

I. M. Grinberg

L. E. Hulbert

A. A. Boiarski

D. E. Niesz

W. M. Pardue (10)

J. E. Davis/ERDA Files 